\title{
The spatial scale of plant-animal interactions: effects of resource availability and habitat structure
}

\author{
Daniel García, ${ }^{1,4}$ Regino Zamora, ${ }^{2}$ and Guillermo C. Amico ${ }^{3}$ \\ ${ }^{1}$ Departamento de Biología de Organismos y Sistemas, Universidad de Oviedo, and Instituto Cantábrico de Biodiversidad \\ (Consejo Superior de Investigaciones Cientificas, Universidad de Oviedo-Gobierno del Principado de Asturias), C/ Rodrigo Uría s/n, \\ Oviedo 33071, Asturias, Spain \\ ${ }^{2}$ Departamento de Ecología, Universidad de Granada, Facultad de Ciencias, Avda. Fuentenueva s/n, Granada 18071, Spain \\ ${ }^{3}$ Laboratorio Ecotono, Instituto de Investigación en Biodiversidad y Medioambiente (Consejo Nacional de Investigaciones Cientificas y \\ Técnicas, Universidad Nacional del Comahue), Bariloche, Río Negro, Argentina
}

\begin{abstract}
Plant-animal interactions are crucial nodes in the structure of communities and pivotal drivers of ecosystem functioning. Much of this relevance may depend on how animals cope with plant resources at different spatial scales. However, little is known about how and why different interactions perform at different scales in the same environmental setting. In this study we assess the spatial scales at which two plant-animal interactions operate and disentangle the environmental factors (plant resource availability vs. habitat structure) underpinning these operational scales. We studied two interactions with opposite (mutualistic vs. antagonistic) ecological effects on fleshy-fruited trees, frugivory and seed dispersal by birds, and the later predation by rodents on bird-dispersed seeds. Employing a standardized sampling, we covered three temperate ecosystems hosting structurally similar plant-frugivoreseed predator systems: Cantabrian forest, Mediterranean shrubland, and Patagonian forest. We sampled habitat structure (tree and understory covers), fleshy-fruit abundance, birddispersed seed occurrence, frugivorous bird abundance, and seed predation rate, along 1500 $2500 \mathrm{~m}$ transects. Using a spatially explicit approach, we broke down the predictable spatial patterns of bird abundance and seed predation rate into patchiness at three consecutive spatial scales (broad, intermediate, and fine). The degree of patchiness and the allocation of spatial variability at different scales suggested a hierarchically nested structure in frugivory and seed predation, but a larger operational scale in seed predation than in frugivory. Scale-specific spatial distributions were explained by the response of animals to plant resource availability and habitat structure. Birds tracked fruits at large spatial scales in all systems and, within some systems, even across consecutive scales. Seed predation distribution was more responsive to habitat features than to resource availability. The reinforcement of resource tracking patterns across scales sometimes occurred simultaneously with the dilution of habitat effects, suggesting that scale dependence may emerge from trade-offs between resource acquisition and the effects of other factors, such as predation risk, on interacting animals. Our findings suggest that scale dependence in frugivory and seed predation may affect the balance of demographic effects of these interactions in plant populations. Moreover, the consistency of frugivory patterns within and across spatial scales may condition the redundancy of seed dispersal as an ecosystem function.
\end{abstract}

Key words: Cantabrian forest, northern Spain; fleshy-fruited plants; frugivory by birds; habitat availability; Mediterranean shrubland, southern Spain; Patagonian forest, Argentina; patchiness; principal coordinates of neighbor matrices (PCNM); resource tracking; scale dependence; seed predation by rodents.

\section{INTRODUCTION}

Spatial scale is a major cause of contingency in ecological systems (Levin 1992). Recognizing that ecological patterns emerge at singular spatial scales, given that they are controlled by multi-scaled processes, is now a central tenet in theoretical ecology and ecosystem management (Levin 1992, Peterson and Parker 1998, Peters et al. 2007). Some of these multiscaled ecological mechanisms are abiotic forces, e.g.,

Manuscript received 5 March 2010; revised 26 May 2010; accepted 25 June 2010. Corresponding Editor: E. T. Borer.

${ }^{4}$ E-mail: danielgarcia@uniovi.es climatic processes, oceanic currents, or fire, that may act upon organisms from local to landscape, or even global, extents (Peterson 2000, Turner et al. 2001). Moreover, among these controlling processes are also biotic interactions between species, such as competition or trophic relationships (Kneitel and Chase 2004). In fact, growing theoretical and empirical evidence points to the multi-scaled functioning of biotic interactions as a determinant of biodiversity generation and species coexistence (Levin 2000, Snyder and Chesson 2004, McCann et al. 2005). For example, competitive exclusion between different species for a limiting resource may be buffered when they share the resource by 

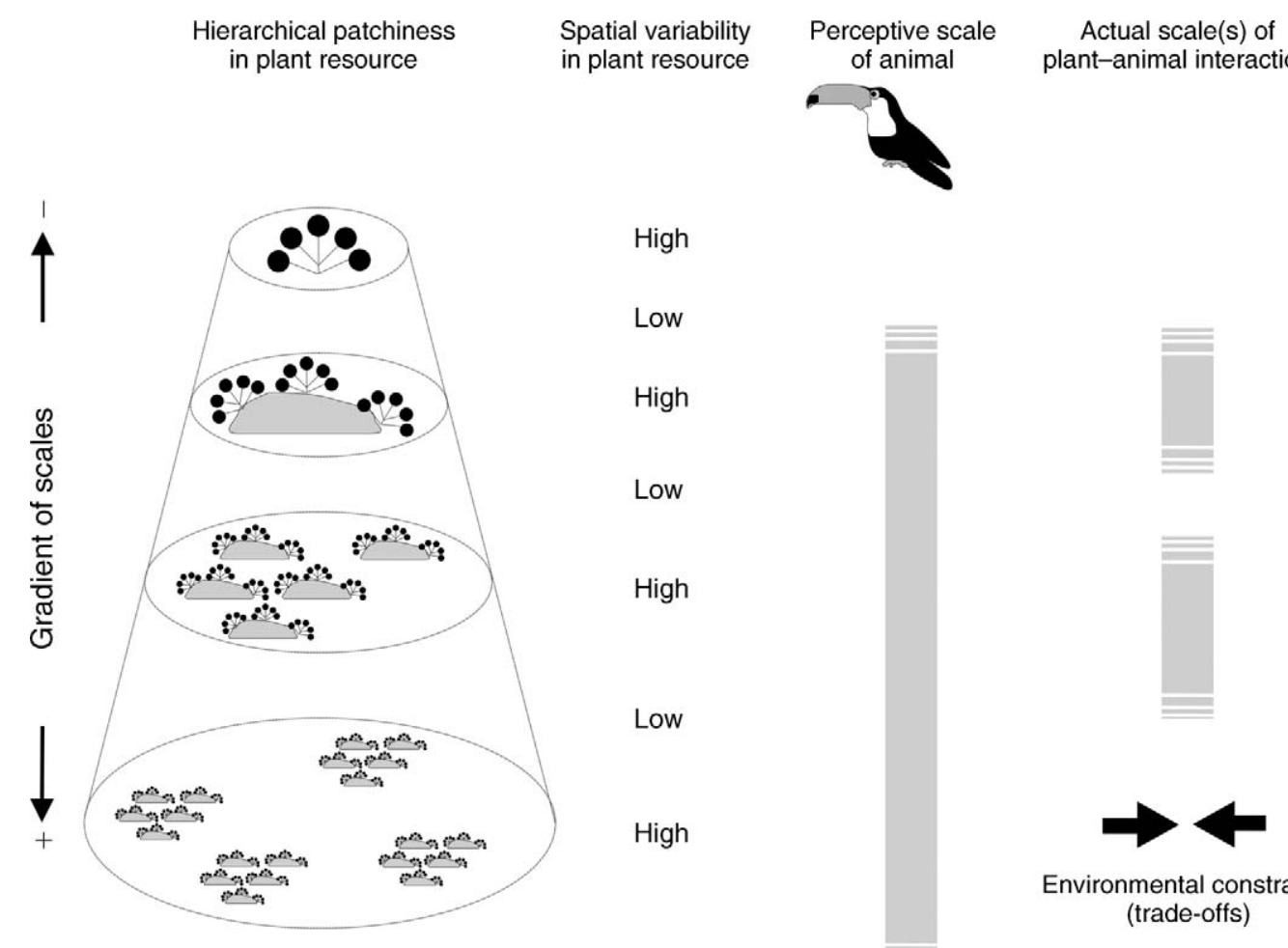

plant-animal interaction

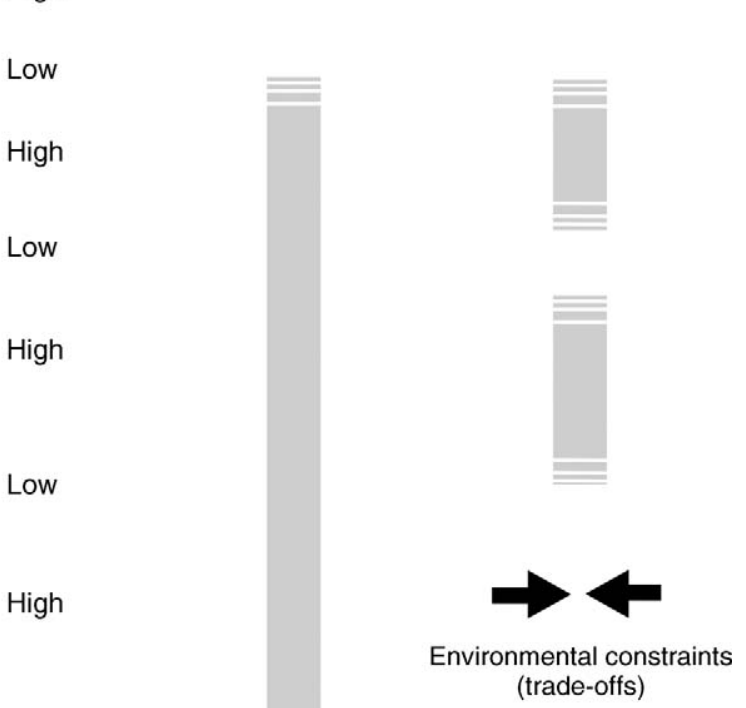

FIG. 1. Conceptual framework for interpreting the spatial scale at which plant-animal interactions (e.g., frugivory by birds) operate. Fruit resources are spatially organized in a patchy fashion along a gradient of scales. Frugivores may or may not show foraging responses to fruit patchiness, depending on their perceptual range and on the diluting effects of environmental factors.

exploiting it at different scales (Inouye 1999, Kneitel and Chase 2004, Westphal et al. 2006). Similarly, scale partitioning and spatial matching of consumer and prey organisms have been suggested as mechanisms controlling the demographic outcomes of food webs, as it happens when predators exert their pressure at progressively wider scales, affecting prey population dynamics and metapopulation structure (Fauchald et al. 2000, Holt 2002, Van Koppel et al. 2005). Finally, the consistency in the outcomes of interspecific interactions across scales has been signaled as a source of functional redundancy that contributes to the resilience of ecosystems (Peterson et al. 1998, Szabó and Meszéna 2006). For instance, different consumers that exert their predatory function over a broad range of scales contribute to enhance the diversity of responses of food webs against a wider range of disturbances (Elmqvist et al. 2003). In sum, the multi-scaled performance of biotic interactions is a pivotal driver of community structure and ecosystem function. However, we are still far from developing general rules to explain how biotic interactions perform at different scales (McCann et al. 2005, Van Koppel et al. 2005). To fill this gap, not only do we need studies addressing the manner in which interactions driven by different organisms perform under a shared spatial framework, but also how generalized the scale- dependent responses of a given interaction across different ecosystems are.

The relationships between plants and their animal consumers are suitable systems for the analysis of scale dependence in interspecific interactions. In fact, processes such as pollination (Leiss and Klinkhamer 2005, Westphal et al. 2006), herbivory (Schaefer and Messier 1995, WallisDeVries et al. 1999), frugivory (Burns 2004, García and Ortiz-Pulido 2004), or seed predation (Curran and Webb 2000) have been demonstrated to be multi-scaled. Nevertheless, the intrinsic and extrinsic mechanisms that determine the specific scales at which animals respond to plant resources are poorly known (Thompson 2002). A first intrinsic driver of spatial idiosyncrasy in plant-animal interactions may be the fact that plants are sessile resources that occur in space in a patchy and hierarchical fashion, with small resource patches nested within larger patches (e.g., fruits clumped within plants, which are clumped within forest patches, which are clumped within landscape units such as valley bottoms or hilltops; Kotliar and Wiens 1990; Fig. 1). This hierarchically nested patchiness means that the spatial variability of the resource provided by plants is allocated along the gradient of scale in a discontinuous way, with sectors of the gradient in which the variability is high and sectors in which the variability is low (Fig. 
1). Thus the distribution of patchiness in plant resources imposes a first template of spatial heterogeneity to which animals may respond or not (García and Ortiz-Pulido 2004, Mayor et al. 2007). This response seems to depend on a second intrinsic mechanism, which is the perceptive scale of the animal, i.e., the spatial extent over which an animal is able to perceive the heterogeneity in resource distribution (see also foraging scale; Wiens 1989, Kotliar and Wiens 1990, Szabó and Meszéna 2006). For example, some frugivores may be unable to cope with heterogeneity in fruit resource abundance at very fine scales due to morphological constraints (e.g., a largebilled frugivorous bird unable to manipulate and select between small fruits within an infructescence; Fig. 1; see also WallisDeVries et al. 1999) or at very large scales due to mobility constraints (e.g., a small-sized frugivore unable to cover large landscape extents exceeding its home range; Spiegel and Nathan 2007).

Extrinsic mechanisms may ultimately constrain the scale-dependent match between plants and animals, even when, at a given scale, plant resources are heterogeneous and animal consumers are sensitive to such heterogeneity. Namely, biotic factors (e.g., risk of predation) or abiotic conditions (e.g., temperature), rather than plant resources, may be the actual environmental drivers of animals' abundance and spatial behavior at specific scales (Fig. 1). For example, the landscape-scale distribution of large herbivores seems to be largely driven by anti-predator behavior, as they select the most protective landscape sectors, irrespective of food plant availability therein (Bowyer and Kie 2006). Thus, the spatial scale of plant-animal interactions may be interpreted as a result of hierarchical, scaledependent balances (trade-offs, sensu Mysterud et al. 1999, Dussault et al. 2005) between plant resource availability and other environmental factors in controlling animals' abundance and activity. In most cases, these limiting environmental factors are well represented by habitat structure (e.g., forest openness represents predation risk for some ungulates, Mysterud et al. 1999). Despite the abundant evidence on the specific spatial responses of different types of plant consumers to habitat and plant resources, there are, to our knowledge, no integrative studies identifying which mechanism, resource availability or habitat structure, goes farthest toward explaining the scale dependence in plant-animal interactions.

In this work, we aim to assess the spatial scales at which plant-animal interactions operate, as well as to unravel the mechanisms underpinning these operational scales. The many ecological and evolutionary outcomes of plant-animal interactions depend strongly on the degree of spatial match between plants, as a resource, and the activity of the interacting animals (Thompson 2002). Thus, we seek to detect scale-dependent spatial matches between the abundance of different plant resources and the activity of different interacting animals, as well as to explain how these matches are conditioned by habitat structure. To do this, we first applied a spatially explicit approach aimed at breaking down the spatial variability in the activity of interacting animals at different spatial scales. Second, we used a mechanistic approach to assess the relative weight of plant resource availability and habitat structure in explaining this scale-dependent variability and which also takes into account the potential relationships between habitat structure and resources.

In order to evaluate the response of interacting animals representing different perceptive scales but coping with a similar environment, we studied two interactions subsequently linked through the life cycle of fleshy-fruited trees: frugivory and seed dispersal by birds and the later predation by rodents on bird-dispersed seeds. These two interactions also represented two different ecological effects on resource plants (the mutualistic seed dispersal vs. the antagonistic seed predation). To discern whether scale-dependent interaction responses were generalized across different ecosystems, our study covered the Cantabrian forest of northern Spain, the Mediterranean shrubland of southern Spain, and the Patagonian forest of southern Argentina. These three temperate ecosystems were chosen as they host structurally similar plant-frugivore-seed predator systems. In all of them, birddispersed plants accounted for a large portion of plant richness and cover within original habitat patches. Frugivore guilds were dominated by passerines that feed almost exclusively on fruits during the fruiting season and disperse the intact seeds. Post-dispersal seed predation was mostly accounted for by rodents, which typically consume a large portion of dispersed seeds and seldom act as secondary seed dispersers. Although the systems differed in biogeographical history and local habitat physiognomy, in all sites we sampled landscape mosaics chosen to represent continuous gradients of habitat and resource availability for frugivores and seed predators.

We sought to fulfil the following specific objectives: (1) to measure the degree of patchiness (i.e., spatial aggregation) in the abundance (or activity) of frugivorous birds and granivorous rodents at different spatial scales; (2) to evaluate to which extent fruit (or seed) resource availability and habitat structure explain the scale-dependent patchiness in frugivory (or seed predation); (3) to ascertain whether the scale-dependent effects of resource availability and habitat structure are generalized among systems or idiosyncratic; (4) to interpret the spatial scale of frugivory (or seed predation) as a result of hierarchical balances between limiting factors (i.e., resource availability vs. other factors molded by habitat structure); and (5) to interpret the relevance of the spatial scale of both frugivory and seed predation in terms of balance between opposite demographic forces, as well as in terms of redundancy of ecological functions within and across spatial scales. 
TABLE 1. Biological description of the studied systems.

\begin{tabular}{|c|c|c|c|c|}
\hline \multirow[b]{2}{*}{ Study area } & \multirow[b]{2}{*}{ Plants } & \multicolumn{3}{|l|}{ Fruit } \\
\hline & & Traits & Season & Ripening peak \\
\hline $\begin{array}{l}\text { Cantabrian } \\
\text { forest }\end{array}$ & $\begin{array}{l}\text { Ilex aquifolium, Crataegus monogyna, } \\
\text { Taxus baccata, Sorbus spp. }\end{array}$ & $\begin{array}{l}10-15 \mathrm{~mm} \text { diameter sugar-rich red } \\
\text { fruits; } 1-4 \text { seeds }(5-9 \mathrm{~mm})\end{array}$ & Sep-Feb & Oct \\
\hline $\begin{array}{l}\text { Mediterranean } \\
\text { shrubland }\end{array}$ & $\begin{array}{l}\text { Berberis hispanica, Juniperus communis, } \\
\text { Lonicera arborea, Amelanchier ovalis, } \\
\text { Crataegus monogyna }\end{array}$ & $\begin{array}{l}6-12 \mathrm{~mm} \text { diameter lipid-rich blue- } \\
\text { black fruits; } 1-4 \text { seeds } \\
(3-7 \mathrm{~mm})\end{array}$ & Sep-Feb & Nov \\
\hline Patagonian forest & $\begin{array}{l}\text { Aristotelia chilensis, Azara microphylla, } \\
\text { Luma apiculata, Schinus patagonicus, } \\
\text { Berberis spp., Maytenus boaria }\end{array}$ & $\begin{array}{l}5-11 \mathrm{~mm} \text { diameter lipid-rich blue- } \\
\text { black fruits; } 1-5 \text { seeds } \\
(1-4 \mathrm{~mm})\end{array}$ & Dec-Mar & Feb \\
\hline
\end{tabular}

Notes: Mean body mass and, for birds, migratory status (R, resident; OI, overwintering individuals; OM, overwintering migrant) are indicated. The study was conducted in the Cantabrian forest of northern Spain, the Mediterranean shrubland of southern Spain, and the Patagonian forest of southern Argentina.

\section{Study Sites And Systems}

Cantabrian forest

The study was carried out in mid-elevation secondary forests of the Cantabrian region (northern Spain; Appendix A: Fig. A1). These forests typically show a uniform tree canopy layer of 5-15 $\mathrm{m}$ high and an almost negligible understory layer of scattered tree saplings, short $(<0.5 \mathrm{~m}$ tall) heaths, and forest herbs. Forest stands occur as variable-sized fragments (from isolated remnant trees to patches of several hectares) embedded in a human deforested matrix of stony pastures and heathland (Erica spp., Ulex europaeus L.) and also as fringe patches, adjacent to mature deciduous forests of beech (Fagus sylvatica L.). The climate is Atlantic. The study area was located in the Sierra de Peña Mayor $\left(43^{\circ} 17^{\prime} \mathrm{N}, 5^{\circ} 30^{\prime} \mathrm{W}, 900 \mathrm{~m}\right.$ above sea level, Asturias Province, Spain). Forests cover $\sim 25 \%$ of the site, the remaining area being covered by pasture and heathland used as cattle rangeland.

The plants of interest in this system are fleshy-fruited trees that account for $\sim 70 \%$ of tree cover in secondary forests (Table 1). Fruits ripen in autumn and are consumed almost exclusively by resident and overwintering thrushes (Turdus spp.) that disperse seeds in their feces (Martínez et al. 2008, García et al. 2010). Carnivorous mammals (fox, badger) may also occasionally consume fruits from basal branches or fruits fallen to the ground. Their contribution to the total, animalgenerated seed rain in the study system is negligible though and is restricted to certain tree species such as yew (Martínez et al. 2008). Once dispersed, seeds may suffer predation by nocturnal mice Apodemus sylvaticus L. and A. flavicollis Melchior (García et al. 2005a). Rodents frequently hoard seeds in trash heaps made at the entrance of their burrows, but they consume almost all hoarded seeds through the winter, and seedling establishment around heaps is rare (García et al. 2005a).

\section{Mediterranean shrubland}

Sampling took place in high-elevation, tree line shrublands of the western Mediterranean Basin (southern Spain; Appendix A: Fig. A1) composed of fleshy- fruited tall shrubs, dry-fruited thorny scrub, and prostrate brooms. The vertical structure of the shrubland shows a uniform shrub layer of $0.5-2 \mathrm{~m}$ high only disrupted by small forest stands or isolated trees (Pinus sylvestris L.) of 5-15 m high. The horizontal structure is variegated, with small shrub patches intermingled with bare ground and rocks. The climate is continental Mediterranean. The study area is located in the Sierra Nevada National Park $\left(37^{\circ} 5^{\prime} \mathrm{N}, 3^{\circ} 28^{\prime} \mathrm{W}, 1900 \mathrm{~m}\right.$ above sea level, Granada Province, Spain). The area has been heavily managed until recent times, with extensive cattle grazing, burning for pastures, forest logging, and pine plantation.

The plants of interest are fleshy-fruited shrubs or small treelets that account for $\sim 70 \%$ of shrub cover (Table 1). Fruits ripen in autumn and are mainly consumed by medium-bodied thrushes and the smallbodied European robin Erithacus rubecula L. (Table 1). Besides the differences in body size, thrushes and robins differ in their patterns of space use: most thrush species are highly vagrant and form flocks of variable size, whereas robins are highly territorial even in winter (Tellería et al. 2008). Seed dispersal by carnivorous mammals only accomplishes a low proportion of animal-generated seed rain in these shrublands (Matías et al. 2008). The seeds of the target shrub species suffer predation after dispersal by A. sylvaticus (GarcíaCastaño et al. 2006, Matías et al. 2009).

\section{Patagonian forest}

The study was carried out in a mid-elevation mature forest of the northwestern Patagonian region (southern Argentina; Appendix A: Fig. A1). The forest has two well-differentiated forest layers, tree canopy reaching up to $40 \mathrm{~m}$ high and understorey reaching up to $7 \mathrm{~m}$ high. Canopy species are Nothofagus dombeyi Mirb. and Austrocedrus chilensis D. Don, whereas the understory comprises up to 15 woody species and the bamboo Chusquea culeou E. Desv. The forest also has canopy gaps generated by tree fall. Forest stands occur as large fragments intermingled with human-generated pastures, crops, and urban areas. The climate is cold temperate. The study was conducted in the Llao-Llao Forest 
TABLE 1. Extended.

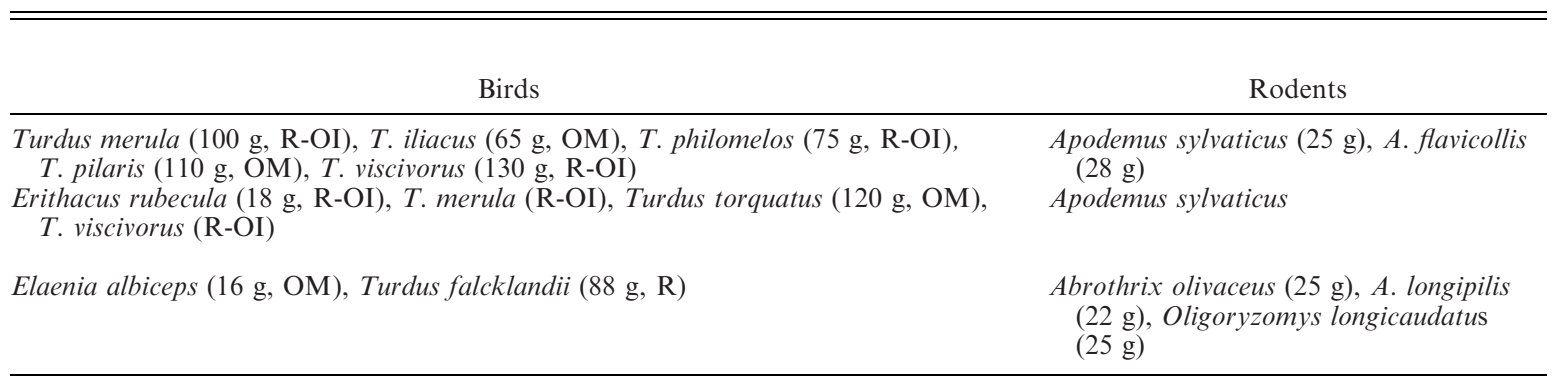

Reserve $\left(41^{\circ} 8^{\prime} \mathrm{S}, 71^{\circ} 19^{\prime} \mathrm{W}, 800 \mathrm{~m}\right.$ above sea level, Río Negro Province, Argentina), which protects a wellpreserved forest that suffered logging and clearing before gaining reserve status.

The plants of interest are fleshy-fruited treelets that account for $\sim 80 \%$ of understory cover (Table 1 ). Fruits ripen in late summer and autumn and are consumed almost exclusively by the small-bodied bird Elaenia albiceps D'Orbigny \& Lafresnaye (Table 1; Amico and Aizen 2005). Frugivory by the nocturnal marsupial Dromiciops gliroides Thomas in fleshy-fruited treelets in the field is occasional, and there is no evidence of fruit consumption by other mammal species (Amico et al. 2009). Post-dispersal seed predation of bird-dispersed seeds is mostly accomplished by small rodents (Table 1). Occasional and negligible seed predation by rhynocriptid ground-feeding birds is also possible (Caccia et al. 2006). Previous works suggest that rodents seldom act as secondary seed dispersers (Caccia et al. 2006, Kitzberger et al. 2007).

\section{Materials And Methods}

\section{Sampling framework}

We sampled habitat features, the abundance of fruits and dispersed seeds, the abundance of frugivorous birds, and the rate of seed predation by rodents across longdistance transects. A single transect, following a straight line, was placed arbitrarily at each study site avoiding large altitudinal gradients $(<250 \mathrm{~m})$ and aiming to represent the whole range of variability in the local landscape (Fig. 2). Transects were $2500 \mathrm{~m}$ long and $20 \mathrm{~m}$ wide and were subdivided into 100 contiguous $25 \times 20 \mathrm{~m}$ plots. (Due to logistical constraints, the transect in the Patagonian forest was $1500 \times 20 \mathrm{~m}$ with $7520 \times 20 \mathrm{~m}$ plots.) Sampling was performed during a single fruiting year, from October 2004 until March 2005 in the Cantabrian forest, October 2005 until March 2006 in the Mediterranean shrubland, and January until March 2005 in the Patagonian forest.

\section{Habitat structure and plant resource availability}

Each plot was divided into $105 \times 10 \mathrm{~m}$ subplots (eight in Patagonian forest) covering the whole area (five at each side of the longitudinal axis of the transect; Fig. 2). For sampling, we chose five (four in Patagonian forest) nonadjacent subplots per plot, sequentially alternating the left and right sides of the transect axis. In these subplots, we visually estimated the total cover (percentage) of tree canopy (woody plants $\geq 10 \mathrm{~m}$ tall) and understory (tree saplings, treelets, and tall shrubs $>0.5$ $\mathrm{m}$ and $<10 \mathrm{~m}$ high; Fig. 2; for suitability of methodology, see García and Chacoff 2007).

We estimated the abundance of fleshy fruits in October in the Cantabrian forest and the Mediterranean shrubland and in January in the Patagonian forest. In the studied localities, fruiting is quite synchronous among individuals and species, with early- or lateripening species being rare, and almost all fruit ripening is delimited to 1-2 months (although fruits remain attached to trees for 1-3 additional months). We thus considered that a single sampling of fruit abundance at the beginning of the season provided an appropriate estimate of the spatial template of fruit resources for frugivores. In each subplot, we identified the species and assigned a standing fruit crop to each individual plant with at least $30 \%$ of its canopy area within the subplot (Fig. 2). Fruit crop size was estimated by means of a fruiting abundance index (FAI; considering six intervals: $0=$ without fruits; $1=1-10$ fruits; $2=11-100 ; 3=101-$ 1000; $4=1001-10000 ; 5>10000$; Saracco et al. 2004). The FAI is strongly correlated to the crop size estimated by direct counting methods $\left(\right.$ crop size $=1.77 \times e^{1.92 \mathrm{FAI}}$; $R^{2}=0.80 ; n=136$ trees in the Cantabrian forest; J. M. Herrera and D. García, unpublished data). We calculated the abundance of fruits per plot as the number of fruits per square meter, by dividing the sum of individual FAIs (translated into interval midpoint values, i.e., $1=5$ fruits; $2=55$; and so on, except in 5 for which we arbitrarily used a value of 25000 ) from all subplots by the sampled surface.

We estimated the occurrence of seeds available for post-dispersal predators after the peak of the seed dispersal season. Bird-generated seed rain in the studied systems is highly heterogeneous in space, especially at very fine scales (e.g., García et al. 2005b). Thus, we considered that any estimation of seed availability should be based on small-sized sampling units largely replicable in each transect plot. In the Cantabrian forest and the Mediterranean shrubland, the frequent damages caused by domestic cattle and wild ungulates on 


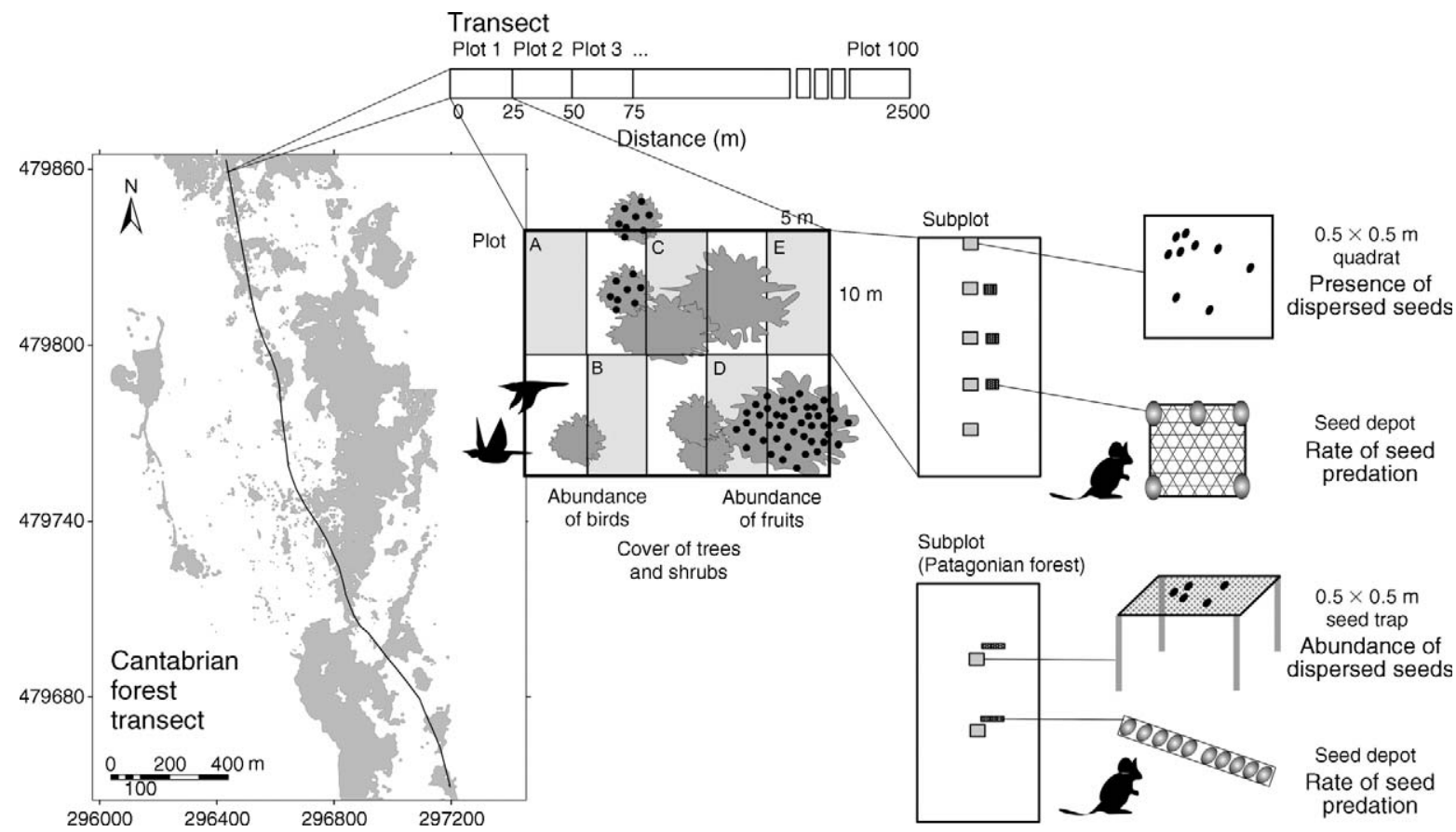

FIG. 2. Design for sampling plant-animal interactions, resource availability, and habitat structure across the landscape. The left panel represents the total extent of the transect (curved line) in the Cantabrian forest (shaded, forest cover; unshaded, deforested matrix). Central panels represent transect subdivision into plots and subplots, for sampling of bird and fruit abundances and habitat features. Right panels represent the design for sampling the availability of dispersed seeds and seed predation rate. The study was conducted in the Cantabrian forest of northern Spain, the Mediterranean shrubland of southern Spain, and the Patagonian forest of southern Argentina. The coordinates are the northings and eastings on a Universal Transverse Mercator (UTM) grid.

experimental devices precluded the use of conventional seed traps for seed dispersal monitoring. Thus, in these sites, we recorded the presence of seeds dispersed by birds in five $0.5 \times 0.5 \mathrm{~m}$ quadrats placed at 2 - $\mathrm{m}$ intervals along each subplot $(n=25$ quadrats per plot, 2500 quadrats per site; Fig. 2).

We assumed that the detection of seeds in open quadrats provides a reliable measure of the initial spatial template of seed availability for post-dispersal seed predators, notwithstanding some early seed removal by rodents, because of the following reasons: (1) seeds found in the remains of birds droppings are very conspicuous and easily distinguishable from the soil background, even when washed by rain; (2) seed removal by diurnal animals was never observed, and removal by nocturnal rodents is low during most of the dispersal season as predation frequency peaks late in winter (García et al. 2005a, Matías et al. 2009); (3) any seed showing signs of predation (open husk or teeth marks) found in the quadrats was considered a dispersed seed; and (4) a previous work in the same Cantabrian site demonstrated the suitability of seed monitoring in quadrats, by comparing seed deposition in quadrats open to predators with seed deposition in paired seed traps that excluded predators (García et al. 2005b).

In the Patagonian forest, due to the low detectability of seeds once deposited on the forest ground (due to small seed size, the dense litter layer, and the scant light at ground level), we discarded the method of open quadrats. Instead, at the beginning of the dispersal season we established two seed traps, $2 \mathrm{~m}$ apart, at the center of each of the two central subplots of each plot (300 traps in total; Fig. 2). Each seed trap consisted of a square, $0.5 \mathrm{~m} \times 0.5 \mathrm{~m}$ wire frame supporting a shallow, open-topped, 1-mm nylon mesh bag, suspended $0.5 \mathrm{~m}$ above the ground on four wire poles. No signs of predation of seeds from within the traps were found during the study.

Seed monitoring in quadrats was performed in early December in the Cantabrian forest and in early January in the Mediterranean shrubland. In the Patagonian forest, the contents of the traps were collected every week until late in March 2007. We estimated the availability of dispersed seeds for predators as the proportion of quadrats containing dispersed seeds per plot ( $n=25$ quadrats) in the Cantabrian forest and the Mediterranean shrubland and as the average cumulative number of seeds of fleshy-fruited plants per trap per plot $(n=4)$ in the Patagonian forest. Although this led to the use of two different parameters for representing seed availability, we considered that, in the Patagonian forest, the proportion of traps containing dispersed seeds would misestimate seed availability at the landscape scale, due to the low number of traps per plot. For 
control purposes, we obtained data for both types of seed availability estimation in the Mediterranean shrubland, from 32 plots where we installed 10 seed traps (28 $\times 18 \times 5 \mathrm{~cm}$ metal trays protected with a $1-\mathrm{cm}$ pore wire mesh) per plot from December 2004 until February 2005. The proportion of quadrats containing dispersed seeds per plot was positively and significantly correlated with the mean number of seeds per trap (Pearson correlation $r=0.473, P \leq 0.01, n=32$ ).

\section{Abundance of frugivorous birds}

Given the logistic difficulties associated with the direct sampling of fruit consumption by birds along the large extent of our sampling framework, we estimated the abundance of frugivores and considered this parameter to be a good estimator of frugivory and seed dispersal. We sought to represent the use of different sampling plots by different quantities of birds over the whole fruiting season. Thus, we distributed the sampling effort throughout the season following the start of sampling. We performed bird censuses 1-3 times per week over 2-3 months (15 censuses per site). For each census, a single watcher travelled the whole transect at a constant speed, between 08:00 and 12:00 on a clear day, recording the number of individuals of different frugivorous species seen or heard within a $25-\mathrm{m}$ wide band at both sides of the transect axis. We estimated the abundance of frugivorous birds as the cumulative number of bird observations per plot for all censuses.

\section{Seed predation}

Granivore activity was estimated from manipulative field sampling that involved the seeds of a single fleshyfruited species in each study system. Spatial patterns of seed predation are highly concordant between cooccurring plant species in the studied ecosystems (García et al. 2005b, Matías et al. 2009), and we thus considered the spatial pattern of predation of this single target species to be representative of community-wide predation trends. Target species were chosen as those previously shown to have intermediate values of abundance and predation rate, relative to co-occurring species (Díaz et al. 1999, García et al. 2005a, Matías et al. 2009). As such, they were Ilex aquifolium in the Cantabrian forest, Berberis hispanica in the Mediterranean shrubland, and Aristotelia chilensis in the Patagonian forest.

In the Cantabrian forest and the Mediterranean shrubland, in mid-January we placed three seed depots per sampling plot, separated by $2 \mathrm{~m}$ and adjacent to the seed sampling quadrats (Fig. 2). Each seed depot consisted of five seeds glued with a low-odor, rain-proof thermoplastic glue to a $50 \times 50 \mathrm{~mm}$ plastic mesh nailed to the ground (García et al. 2005a). In the Patagonian forest, in late February we placed one seed depot under each seed trap described above (four depots per plot), each depot consisting of 10 seeds glued over a $12 \mathrm{~cm}$ long, horizontal wooden stick nailed to the ground (Fig.
2). We monitored seed depots two weeks after installation, counting the number of intact seeds, the number of seeds showing signs of predation (gnawed coats and eaten embryos), and the number of seeds removed. Seed predation rate was calculated as the proportion of consumed seeds (both gnawed and removed seeds) relative to the initial number of seeds in all depots of each plot.

\section{Statistical Analysis}

\section{Spatial structure of bird abundance and seed predation at multiple scales}

We sought to examine the spatial structure of bird abundance and seed predation at different scales, in the different study systems, by evaluating the spatial patchiness of these variables (i.e., by examining the number and shape of the patches along the transect), as well as by breaking down their spatial variability, at different scales. We considered that bird abundance and granivory by rodents may present aggregated spatial structures along a hierarchy, or gradient, of scales, with larger patches containing smaller ones. In analytical terms, such a hierarchical patchiness corresponds to the well-defined allocation of the spatial variance of bird abundance or seed predation at several scales along the gradient (Borcard and Legendre 2002).

Our sampling framework was a 2500 -m linear transect with 100 equidistant sampling points $(1500 \mathrm{~m}$ with 75 points for Patagonian forest), in which all sampled biological variables were spatially referenced to the onedimensional geographic coordinate of the centroid of the plot (i.e., the distance along the transect; the first plot referring to zero, the second plot to $25 \mathrm{~m}$, and so on, the last plot to $2475 \mathrm{~m})$. We considered that the unidimensional structure of the framework would not be a handicap in detecting patchiness in the ecological objects of interest (plant cover, fruits and seeds, birds, rodents). We assumed that the processes underpinning the patterns of patchiness in frugivory and seed predation were isotropic and that the spatial resolution of the sampling scheme was strong enough to detect patchy distributions in all the ecological variables of interest. The gradient of scales under study ranged from the spatial dimension represented by the transect grain $(25$ $\mathrm{m}$, the distance between plot centroids) to that represented by the transect extent $(2500 \mathrm{~m})$.

We were first interested in identifying the spatial structure of frugivory and seed predation across a continuous gradient of scales arbitrarily defined within the sampling scheme of each study system. For this, we used a principal coordinates of neighbor matrices analysis (PCNM; Borcard and Legendre 2002). The PCNM analysis is a tool for identifying relationships between ecological descriptors (e.g., the magnitude of a plant-animal interaction) and environmental factors (e.g., habitat features, resource availability) at multiple spatial scales by, first, identifying significant spatial structures in the ecological descriptors along the 
gradient of scales and, second, relating the form of these scale-specific spatial structures to environmental factors (Borcard et al. 2004, see also a similar application in García et al. 2009 and references therein).

The PCNM method starts by creating a set of spatial variables (PCNM vectors, generated using SpaceMaker 2 software; Borcard and Legendre 2004) that represent all scales that the sampling scheme can perceive. (A comprehensive description of PCNM is shown in Appendix B.) In the case of a linear transect, the PCNM vectors are a series of sine waves with progressively decreasing periods, representing a gradient of templates with periodic patches of progressively smaller diameters, from the broadest PCNM1 to the finest PCNM67 (PCNM1 to PCNM50 in the Patagonian forest). These PCNM vectors were used to detect the scale-dependent spatial variability of a given sampled response variable (the abundance of birds, the rate of seed predation) by considering them as predictors in a multiple regression model. Prior to this multiple regression, the response variable was checked for linear trends, in order to detrend spatial structures at a scale larger than that covered by the whole sampling extent. The PCNM vectors that showed significant partial regression fits were selected to build a global spatial model, whose coefficient of determination $\left(R^{2}\right)$ indicated the predictable spatial variability of the response variable. Once built, the global spatial model was arbitrarily partitioned into several additive submodels, which accounted for the spatial variability at different, but contiguous, portions of the gradient of scale within the sampling extent. For this, each significant PCNM vector was assigned to one of three groups representing three equitable sections of the whole gradient of spatial templates (from PCNM1 to PCNM67): broad, intermediate, and fine scales. The multiple regression fits of these spatial submodels provided predicted values of the response variable for all plots in the transect. These PCNM predicted values of a given response variable were considered as the surrogates of its spatial variability and, plotted against the distance along the transect, were used to interpret the shape and size of its patches at different spatial scales.

In those cases in which the guild of frugivorous birds was composed of species with large differences in body size and assumed spatial behavior (vagrant vs. territorial), we performed separate analyses of spatial patterns for each species. This was only possible in the case of the Mediterranean shrubland, where we distinguished between E. rubecula and Turdus spp. abundances. Small abundances of frugivores other than E. albiceps precluded this sort of comparison in Patagonian forest.

\section{Scale-dependent effects of resource availability} and habitat features on frugivory and seed predation

We evaluated how the spatial structure of plantanimal interactions at different scales was conditioned by, simultaneously, fruit/seed resource availability and habitat structure by means of structural equation models (SEM; Grace 2006). Structural equation models (e.g., path analysis) state a causal scheme, or path diagram, that represents a series of causal links based on a priori knowledge or logical relationships within a group of variables, thus allowing the partitioning of correlation between variables into direct and indirect effects. Direct effects are represented by links between consecutive variables and are measured by standardized regression coefficients.

Considering the abundance of frugivorous birds and the rate of seed predation as ultimate response variables, we hypothesized, in separate causal models, that these interactions were potentially affected by the direct effect of resource abundance (as birds may track for fruit resources and rodents may track for fruits fallen under trees and for seeds dispersed by birds), as well as by the direct, independent effects of habitat structure, represented by forest tree and understory covers (as both birds and rodents may search for protective canopies to avoid their own predators, to rest, or to forage on nonfruit resources). We also included in the models indirect effects of interactions between habitat features and resource availability. In the case of the abundance of birds, indirect effects were represented by the links between forest cover and fruit abundance (fruit availability may depend on the cover of fruit-bearing trees; tree canopy may overshadow the understory, hampering fruit production), the link between shrub cover and fruit abundance (fruit availability may depend on shrub cover), and the link between forest cover and shrub cover (tree canopy may outcompete shrubs). In the case of seed predation by rodents, indirect effects also included the link between fruit abundance and the frequency of occurrence of dispersed seeds (as more seeds may occur in fruit-rich patches if avian frugivores track for fruits; García et al. 2010).

Each causal scheme was checked at different spatial scales, by repeatedly running a given path model with the values of a given response variable (frugivorous bird abundance, seed predation rate) predicted by the different PCNM submodels (Borcard et al. 2004). In the Mediterranean shrubland data set, we performed separate analyses for E. rubecula and Turdus spp. We performed SEMs only with those predicted response variables emerging from statistically significant spatial submodels $\left(R^{2} \geq 0.05, P<0.05\right)$. Models were performed using maximum likelihood discrepancy functions, and the proportion of variance of the response variables explained by their predictors was estimated from squared multiple correlation coefficients. In each model, the nonsignificant paths were sequentially removed from the saturated model until the best fit model was achieved as determined by the Akaike information criterion (AIC). Path analyses were performed with AMOS 16.0 software (Arbuckle 2007). Explanatory variables were used with their actual values in all path models, but were transformed (arcsine square 
TABLE 2. Per plot values (mean $\pm \mathrm{SE}$ ) of the abundance of frugivorous birds, the rate of seed predation, the abundance of fruits available to frugivores and dispersed seeds available to seed predators, and habitat features in the transects at the three study areas.

\begin{tabular}{lccc}
\hline \hline Parameter & $\begin{array}{c}\text { Cantabrian forest } \\
(n=100 \text { plots })\end{array}$ & $\begin{array}{c}\text { Mediterranean shrubland } \\
(n=100 \text { plots })\end{array}$ & $\begin{array}{c}\text { Patagonian forest } \\
(n=75 \text { plots })\end{array}$ \\
\hline Abundance of frugivorous birds & $17.9 \pm 2.2$ & $9.0 \pm 1.5$ & $7.9 \pm 0.5$ \\
Abundance of Erithacus rubecula & $\ldots$ & $2.0 \pm 0.3$ & $\ldots$ \\
Abundance of Turdus spp. & $\ldots$ & $6.9 \pm 1.3$ & $\ldots$ \\
Seed predation rate $($ proportion $)$ & $0.47 \pm 0.02$ & $0.06 \pm 0.01$ & $0.78 \pm 0.03$ \\
Fruit abundance (no./ $\mathrm{m}^{2}$ ) & $138.2 \pm 15.3$ & $73.7 \pm 9.5$ & $24.1 \pm 4.7$ \\
Proportion of samples with dispersed seeds & $0.54 \pm 0.03$ & $0.12 \pm 0.01$ & $\ldots$ \\
Number of dispersed seeds per trap & $32.4 \pm 2.7$ & $1.8 \pm 0.6$ & $1.8 \pm 0.3$ \\
Percentage of forest cover & $\ldots$ & $50.8 \pm 1.6$ & $71.7 \pm 3.3$ \\
Percentage of understory/shrub cover & $\ldots$ & $73.0 \pm 2.8$ \\
\hline
\end{tabular}

Note: Two types of birds (Erithacus rubecula vs. Turdus spp.) are differentiated in the Mediterranean shrubland.

root, for covers; $\log (x+1)$, for abundances) prior to analyses.

\section{RESULTS}

Overview of plant-animal interactions, resource abundance, and habitat structure at different sites

The study systems differed strongly in the abundance of birds and the rate of seed predation by rodents (Table 2). The frequency of occurrence of frugivorous birds was high in all transects. The most frequent bird species were; in the Cantabrian forest, Turdus iliacus and T. merula (71\% and 14\%, respectively; 1904 recordings), in the Mediterranean shrubland, T. torquatus, Erithacus rubecula, and T. merula $(56 \%, 18 \%$, and $12 \%$, respectively; 1150 recordings), and in the Patagonian forest, E. albiceps (97\%; 616 recordings). Seed losses due to predation by rodents were also widespread across transects, but very different in the average magnitude among systems (high in the Cantabrian forest and the Patagonian forest, but low in the Mediterranean shrubland; Table 2).

The major fruiting species were Ilex aquifolium (Cantabrian forest, $58 \%$ of total crop), Berberis hispanica (Mediterranean shrubland, $83 \%$ of crop), and Aristotelia chilensis (Patagonian forest, 80\% of crop). Mean fruit abundance and the frequency of occurrence of dispersed seeds were higher in the Cantabrian forest than in the Mediterranean shrubland or the Patagonian forest (Table 2). Habitat structure was also different between systems. The Cantabrian forest showed moderate but widespread cover of tree canopy along the transect, whereas the Mediterranean shrubland showed low and occasional forest cover but high and widespread shrub cover. Forest and understory covers were high in the Patagonian forest.

\section{Spatial patchiness of bird abundance and seed predation at multiple scales}

The PCNM analyses showed that both the abundance of birds and the rate of seed predation showed nonrandom spatial structures at different spatial scales, in all studied systems. The number of spatial predictors (from the 67 vectors generated by the PCNM analysis in the 100-plot linear transects [50 in the 75-plot transect]) that accounted significantly for spatial variation ranged from 17 (in the case of the abundance of Turdus spp. in the Mediterranean shrubland) to 6 (in the case of the rate of seed predation in the Mediterranean shrubland; Table 3). Depending on the system, PCNM vectors accounted for between $61 \%$ and $83 \%$ of the predictable spatial variance in the abundance of frugivorous birds along the transect (Table 3). Similar values of explained spatial variance emerged from PCNM analyses in the case of seed predation rate, except in the Mediterranean shrubland, where PCNM vectors accounted for $<33 \%$ of variance. In all cases, most significant PCNM vectors were incorporated into the submodels at broad and intermediate scales. Patchiness at the broad scale was always better predicted than that at the intermediate scale, and no significant nonrandom spatial structures were detected at the finest scale in any case. The spatial variance of bird abundance was allocated between the broad and the intermediate scales more equitably than in the case of seed predation rate, in which the broadscale submodel accumulated $>75 \%$ of explained variance in all study systems but one (Table 3 ).

The representation of the PCNM predicted values for the abundance of frugivorous birds and the seed predation rate at the broad and the intermediate scales suggested strong patchiness at both these spatial scales (Figs. 3 and 4). The number and shape of the patches along transects nevertheless differed between plantanimal interactions and, to a lesser extent, among systems. The abundance of frugivorous birds was distributed in numerous patches at both the broad and the intermediate scales in all systems, with smaller $(\sim 120$ $\mathrm{m}$ long on average) patches included within larger $(\sim 320$ $\mathrm{m}$ long on average) ones (Fig. 3). In the Mediterranean shrubland, the predicted abundance of the small frugivorous $E$. rubecula mirrored that of the bigger Turdus spp., at both the broad and the intermediate scales (Fig. 3), indicating similar spatial patterns between the different frugivores. Somewhat different to the abundance of frugivorous birds, seed predation rate showed a pattern of patchiness characterized by the presence of a few, very large (500-700 $\mathrm{m}$ long on 
TABLE 3. Summary of multiple regression models fitting the abundance of frugivorous birds (log transformed) and the rate of seed predation (arcsine square-root transformed) to principal coordinates of neighbor matrices (PCNM) vectors in different study systems.

\begin{tabular}{|c|c|c|c|c|c|c|c|c|c|c|}
\hline \multirow[b]{3}{*}{ Parameter and scale } & \multirow{2}{*}{\multicolumn{2}{|c|}{$\begin{array}{l}\text { Cantabrian } \\
\text { forest }\end{array}$}} & \multicolumn{6}{|c|}{ Mediterranean shrubland } & \multirow{2}{*}{\multicolumn{2}{|c|}{$\begin{array}{l}\text { Patagonian } \\
\text { forest }\end{array}$}} \\
\hline & & & \multicolumn{2}{|c|}{ E. rubecula } & \multicolumn{2}{|c|}{ Turdus spp. } & \multirow[b]{2}{*}{$\begin{array}{l}\text { No. } \\
\text { vectors }\end{array}$} & \multirow[b]{2}{*}{$R^{2}$} & & \\
\hline & $\begin{array}{c}\text { No. } \\
\text { vectors }\end{array}$ & $R^{2}$ & $\begin{array}{l}\text { No. } \\
\text { vectors }\end{array}$ & $R^{2}$ & $\begin{array}{l}\text { No. } \\
\text { vectors }\end{array}$ & $R^{2}$ & & & $\begin{array}{l}\text { No. } \\
\text { vectors }\end{array}$ & $R^{2}$ \\
\hline \multicolumn{11}{|l|}{$\begin{array}{l}\text { Frugivorous birds } \\
\text { abundance }\end{array}$} \\
\hline Broad scale & 9 & $0.43 * * *$ & 11 & $0.53 * * *$ & 10 & $0.61 * * *$ & & & 6 & $0.36^{* * *}$ \\
\hline Intermediate scale & 6 & $0.23^{* * *}$ & 4 & $0.20 * * *$ & 5 & $0.18^{*}$ & & & 4 & $0.22 * *$ \\
\hline Fine scale & 1 & $0.02 \mathrm{NS}$ & 1 & $0.02 \mathrm{NS}$ & 2 & $0.04 \mathrm{NS}$ & & & 1 & $0.03 \mathrm{NS}$ \\
\hline Total $R^{2}$ & & $0.68^{* * *}$ & & $0.75^{* * *}$ & & $0.83^{* * *}$ & & & & $0.61 * * *$ \\
\hline \multicolumn{11}{|l|}{ Seed predation rate } \\
\hline Broad scale & 7 & $0.63^{* * *}$ & & & & & 3 & $0.21 * * *$ & 7 & $0.52 * * *$ \\
\hline Intermediate scale & 3 & $0.06 \mathrm{NS}$ & & & & & 3 & $0.11^{* *}$ & 3 & $0.11 * *$ \\
\hline Fine scale & 1 & $0.02 \mathrm{NS}$ & & & & & 0 & $\cdots$ & 2 & $0.05 \mathrm{NS}$ \\
\hline Total $R^{2}$ & & $0.71 * * *$ & & & & & & $0.32 * * *$ & & $0.68 * * *$ \\
\hline
\end{tabular}

Notes: Regressions used the residuals of fitting the dependent variables to the one-dimensional coordinate of the sampling plots in those cases in which these variables showed significant linear trends. The number of significant PCNM vectors for spatial submodels that represented three progressively finer scales, the coefficient of determination $\left(R^{2}\right)$ for the total spatial model, and the degree of significance are also shown. Two types of birds (Erithacus rubecula vs. Turdus spp.) are differentiated in the Mediterranean shrubland.

** $P \leq 0.01 ; * * * P \leq 0.001 ; \mathrm{NS}, P>0.05$.

average), broadscale landscape patches that accounted for most spatial predictability (Fig. 4). This spatial pattern was specially marked in the case of the Cantabrian forest, where two large patches of predicted high values of seed predation were separated by a central valley of low values.

\section{Scale-dependent effects of resource availability and habitat structure on frugivory and seed predation}

The structural equation models revealed significant effects of both resource (fruits or seeds) abundance and habitat features on the predicted spatial distributions of both frugivory and seed predation at different spatial scales. In the case of frugivory, represented by the abundance of frugivorous birds, the abundance of fleshy fruits was a pervasive predictor of the predicted PCNM values at the broad scale, suggesting that, in all studied systems, broadscale patches of birds abundance matched fruit-rich sectors of the habitat (Figs. 5 and 6). In the Cantabrian forest, $41 \%$ of the variance in the PCNM values was explained by the positive effect of fruit abundance, by the indirect effect of forest cover on fruit abundance (as both variables were positively correlated), and by the small but direct effect of forest cover. In the other systems, forest cover was a significant and positive predictor of broadscale patchiness in bird abundance, especially in the Patagonian forest, where the direct effect of this habitat feature was even stronger than that of fruit abundance. Structural equation models also evidenced indirect effects mediated by the effects of forest and shrub covers on fruit abundance. For example, clumps of fruiting plants occurred in highly forested and shrub-covered habitat sectors in the Mediterranean shrubland, but occurred in the more cleared forest patches in the Patagonian forest. In the Mediterranean shrubland, both Turdus spp. and E. rubecula showed a similar pattern of broadscale response to fruit abundance and forest cover. On the other hand, SEMs were weaker predictors of the spatial distribution of the abundance of frugivorous birds at the intermediate scale (Fig. 6). In the Patagonian forest, fruit abundance by itself explained a significant fraction of the intermediate-scale spatial patchiness in the abundance of birds. In the other two systems, the combined direct effects of forest cover and fruit abundance were marginally significant (Cantabrian forest) or null (Mediterranean shrubland).

The intercorrelated effects of fruit and seed abundances and habitat features also explained the multi-scaled spatial patterns of seed predation (Figs. 5 and 7). Nevertheless compared to frugivory, the predictive power of SEMs with seed predation was lower, and the relative effects of resource abundance and habitat features varied strongly among study systems. In the Cantabrian forest, the direct effects of forest cover, fruit abundance, and the occurrence of dispersed seeds explained $12 \%$ of the variability in the broadscale spatial patterns of seed predation (Fig. 7). The large patches of high seed predation rate occurred mostly in highly forested, fruitand seed-rich sectors of habitat (Fig. 5). The direct effects of both fruit and seed abundance on seed predation were, however, negative, suggesting that, when controlling for the positive effects of forest cover, seed predation was lower in areas with a high density of fruit and seed resources. Conversely, in the Mediterranean shrubland, the only factor affecting the broadscale patterns of seed predation was the magnitude of seed dispersal, and this effect was positive (Figs. 5 and 7). Finally, in the 

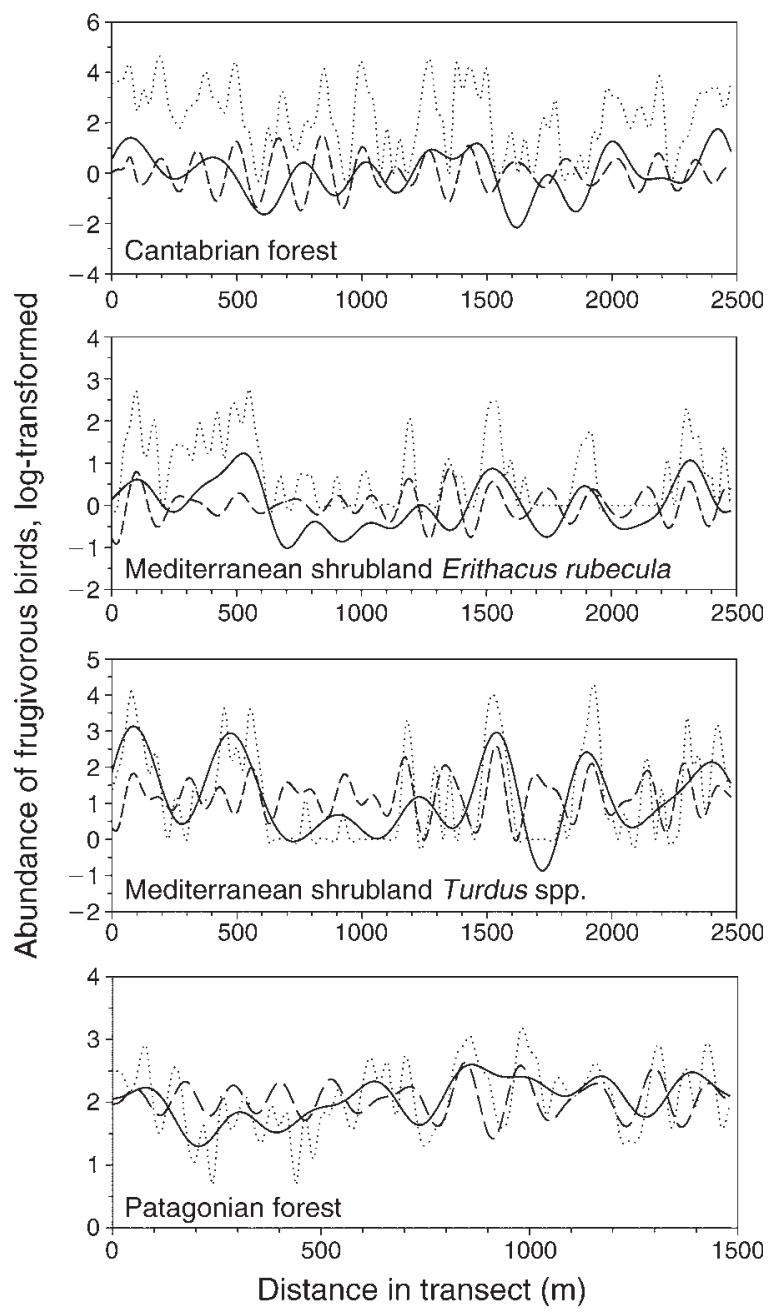

FIG. 3. Abundance of frugivorous birds in the three study systems, along 2500-m (1500-m in the Patagonian forest) sampling transects. Abundances of Erithacus rubecula and Turdus spp. are distinguished in the Mediterranean shrubland. The log-transformed (and smoothing-spline-fitted) raw values (dotted line) and the values predicted by the principal coordinates of neighbor matrices (PCNM)-based spatial submodels at different spatial scales (broad, continuous line; intermediate, dashed line) are distinguished. Values predicted by the PCNM spatial submodels have been calculated by applying multiple regression models on log-transformed bird abundance.

Patagonian forest, shrub cover explained $42 \%$ of the spatial variability in seed predation at the broad scale, indicating larger predation in dense shrub cover areas (Figs. 5 and 7). This habitat effect on seed predation also emerged at the intermediate scale, together with a significant and positive effect of fruit abundance (Fig. 7).

\section{DisCUSSION}

\section{General overview}

We studied three plant-frugivore-seed predator systems that, in terms of quantitative features, such as species richness and relative abundances of fleshy-fruited plants, fruits, seeds, and birds, and seed predation magnitudes, were similar to those from other localities in the Cantabrian range (e.g., Guitián and Munilla 2008), the Mediterranean mountains (e.g., Tellería et al. 2008, Matías et al. 2009), and the Patagonian forest (e.g., Aizen et al. 2002). Seed predation in the Patagonian forest showed mean values larger than previously reported (e.g., Díaz et al. 1999, Caccia et al. 2006), a result potentially related to the methodology used, as predators may have been more attracted to seed depots when covered by seed traps. Recorded abundances of fruits and birds and seed predation rate were within the range of values found in pluri-annual studies carried out in the same or similar localities in all studied systems (e.g., Guitián and Bermejo 2006, Herrera and García 2009, Matías et al. 2009). Thus, we are interpreting the scale-dependent responses of plant-animal interactions based on data representative of the spatiotemporal patterns of the abundance of plant resources and the activity of consumer animals found in the same or in similar study systems.

In this work, we aimed to identify the spatial scale at which different plant-animal interactions emerge by demonstrating scale-dependent matches between plant resources and the abundance or the activity of interacting animals. Analyzing three distinct temperate systems,
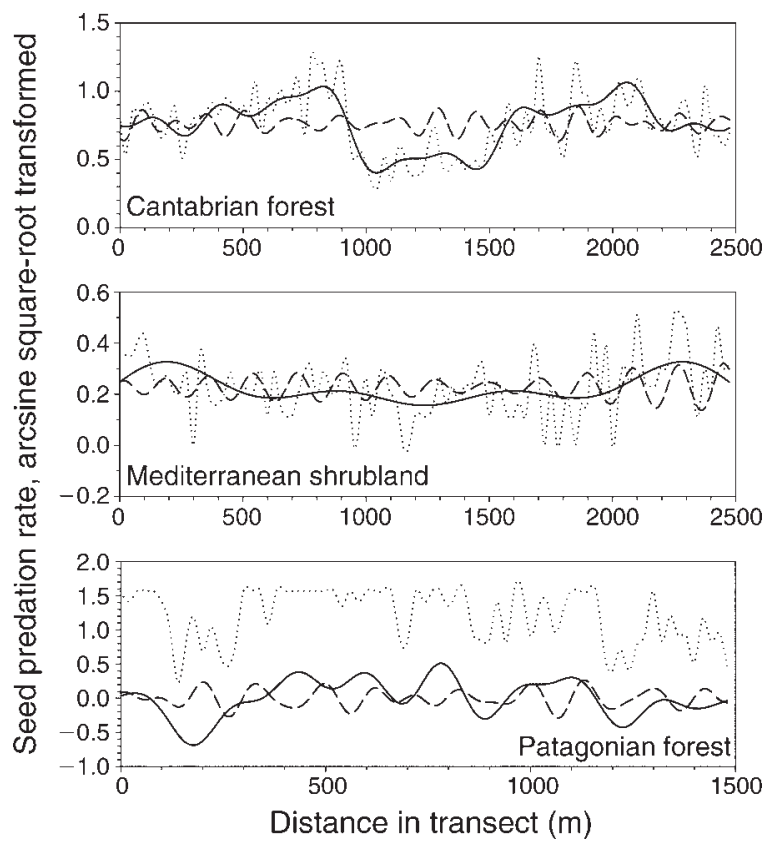

FIG. 4. Seed predation rate in the different study systems, along $2500-\mathrm{m}(1500-\mathrm{m}$ in the Patagonian forest) sampling transects. The arcsine square-root-transformed (and smoothing-spline-fitted) raw values (dotted line) and the values predicted by the principal coordinates of neighbor matrices (PCNM)-based spatial submodels at different spatial scales (broad, solid line; intermediate, dashed line) are distinguished. Seed predation rate was measured as the proportion of consumed seeds per plot. 

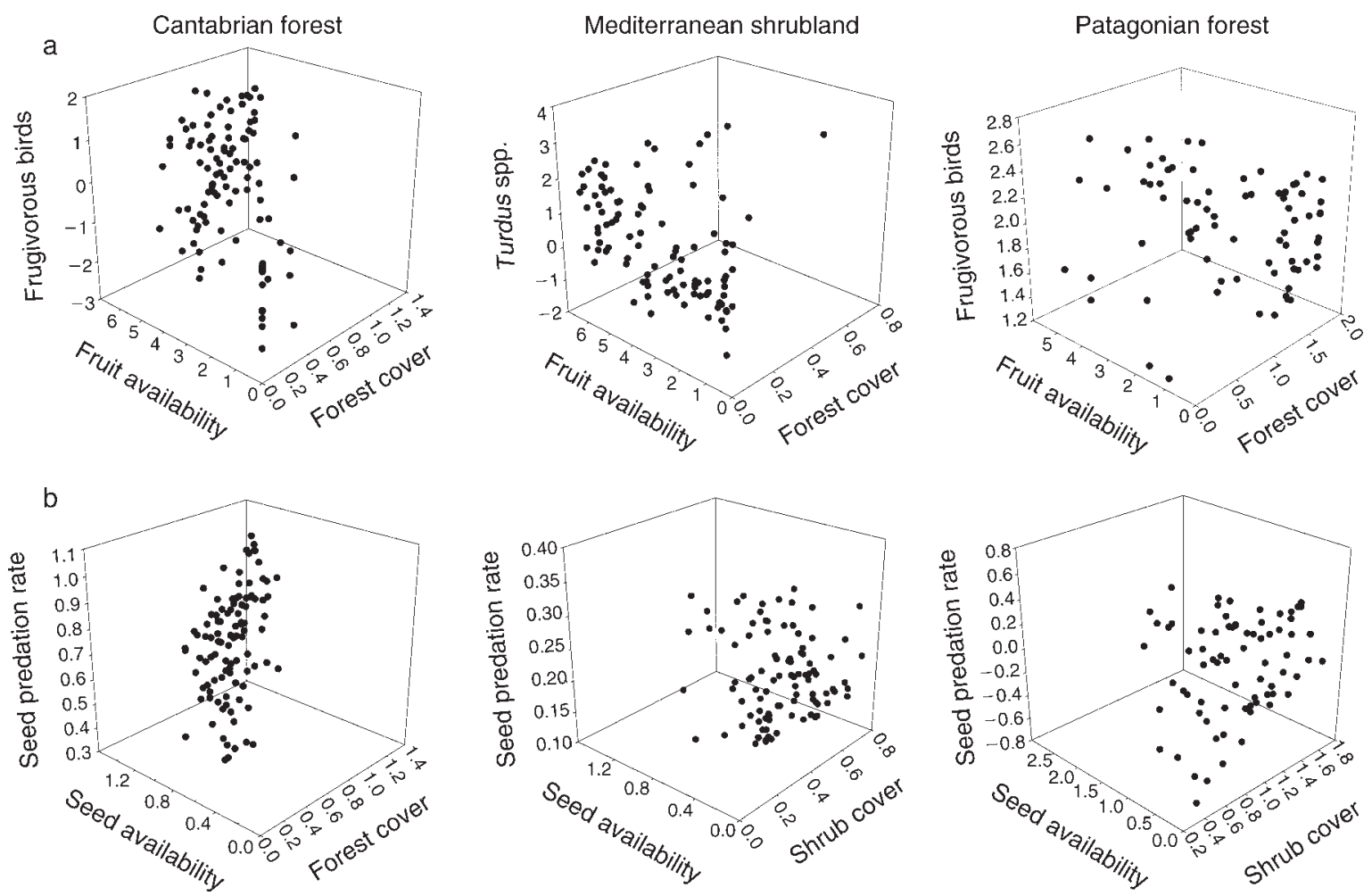

FIG. 5. (a) The abundance of frugivorous birds and (b) the rate of seed predation and as a function of resource availability (fruit abundance, upper row; frequency of occurrence of seeds or abundance of seeds, lower row) and forest or shrub cover in the three study systems (solid circles represent different plots along the sampling transects). All variables were log (abundances) or arcsine (proportions) transformed for representation purposes and were originally measured as follows: fruit availability, no. fruits/ $\mathrm{m}^{2}$; seed availability, proportion of sampling quadrats containing dispersed seeds per plot (Cantabrian forest and Mediterranean shrubland) or number of dispersed seeds per trap per plot (Patagonian forest); forest cover, proportion of tree canopy cover per plot; shrub cover, proportion of understory/shrub cover per plot.

we consistently found that the abundance of frugivores and the activity of seed predators varied in space in a scale-dependent manner. We have demonstrated that this scale-dependent variability was partially predicted by the availability of resources provided by plants, especially in the case of avian frugivores, and by habitat structure, especially in the case of seed predation by rodents. The allocation of spatial variability across scales and the relative weight of environmental variables on the functioning of the interactions depended on both the interaction type and the study system. In the following sections, we will discuss these contingencies and interpret the global outcomes and ultimate consequences of the scale-dependent performance of frugivory and seed predation.

\section{Spatial scale and environmental correlates of frugivory by birds}

The abundance of frugivorous birds showed patchy distributions at all identified spatial scales in all studied systems. Patchiness in bird abundance was hierarchically nested, as larger patches themselves contained smaller ones (see similar patterns in Fauchald et al. 2000, García et al. 2009, Wehnke et al. 2009). Comparing systems, average patch sizes of bird abundance at the broad and intermediate scales were very similar in the Cantabrian forest and the Mediterranean shrubland, but comparatively narrower in the Patagonian forest (Fig. 3). The composition of the associated frugivorous guilds could explain these similarities and differences in patch size. Namely, the smaller and more sedentary E. albiceps of the Patagonian forest may have shown narrower foraging scales than the larger and more vagrant Turdus spp., dominant in the other two systems. In fact, it has been proposed that the perceptual range of frugivorous birds correlates with body size, with bigger frugivores showing wider individual home ranges and, hence, larger population clumps (Spiegel and Nathan 2007). Nevertheless, within the Mediterranean shrubland, co-occurring species with contrasted body size and vagility (the small and territorial E. rubecula vs. the large and vagrant Turdus spp.) showed a similar spatial distribution at the different scales. These species were rarely recorded simultaneously in the same sampling plots during bird censuses (from 403 occurrences of E. rubecula and/or Turdus spp. detected along the transect plots, only $22 \%$ corresponded to co-occurrences). Thus, the spatial concordance between frugivores seems to result from 


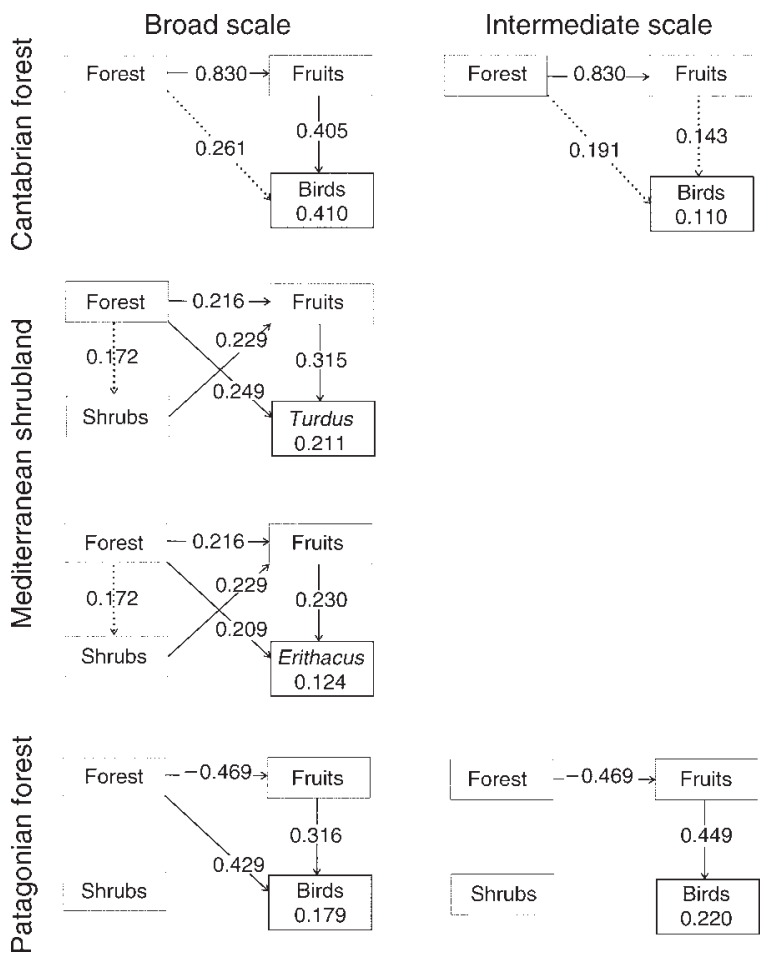

FIG. 6. Structural equation models relating the abundance of frugivorous birds (Birds) predicted by the principal coordinates of neighbor matrices (PCNM)-based spatial submodels at broad and intermediate spatial scales to the abundance of fruits (Fruits), tree canopy cover (Forest), and cover of understory shrubs (Shrubs) in the three study systems. Abundances of Erithacus rubecula and Turdus spp. are distinguished in the Mediterranean shrubland. The schemes represent the causal links included in the best-fit models and indicate the sign and the magnitude of the standardized partial regression coefficients of each link (continuous line, $P<0.05$; dotted line, $P<0.10$ ). Squared multiple correlation coefficients $\left(R^{2}\right)$ are also shown in the boxes of the response variable.

an independent response to similar environmental factors.

The structural equation models suggested that the availability of fleshy fruits and habitat structure were surrogates of the ecological mechanisms responsible for the scale-dependent patterns of bird distribution. In all studied ecosystems, and independently of the effect of habitat structure, large-scale bird clumps occurred in fruit-rich patches, suggesting a pervasive and generalized process of fruit resource tracking across the whole landscape. Large-scale fruit tracking by birds has been evidenced for other temperate and non-temperate ecosystems (e.g., Whitney and Smith 1998, Tellería and Pérez-Tris 2003, Guitián and Munilla 2008, Wehnke et al. 2009). Strong vagility, flocking behavior, and an almost exclusively fruit-based diet of temperate migrant passerines during autumn and winter (e.g., Turdus spp.; Rey 1995, Tellería et al. 2005) would promote the spatial match between fruits and birds throughout the landscape. In fact, in the systems in which bird populations were dominated by migrant individuals and species (i.e., the Cantabrian forest and the Mediterranean shrublands), fruit availability was the major environmental predictor of bird abundance.

A complementary role of forest cover in shaping the broadscale distribution of bird abundance was also detected in the Cantabrian forest and, remarkably, in the Mediterranean shrubland. This indicated that birds accumulated disproportionately in patches with higher tree cover, independently of the quantity of fruits. These results contrast with those by Tellería et al. $(2005,2008)$ who, working with different Mediterranean shrubland localities across a regional extent, found no direct effect of habitat structure on the abundance of frugivorous passerines. In our landscape-based study, the search for areas providing protection against predators (Sapir et al. 2004), or even for perching structures used as stepping stones when foraging across the fragmented landscape (Herrera and García 2009), would explain the effect of tree cover. Besides these direct effects, forest cover and, in the case of the Mediterranean shrubland, shrub cover mostly affected the broadscale distribution of birds by means of indirect effects, that is, by controlling the distribution and abundance of fleshy fruits across the landscape.
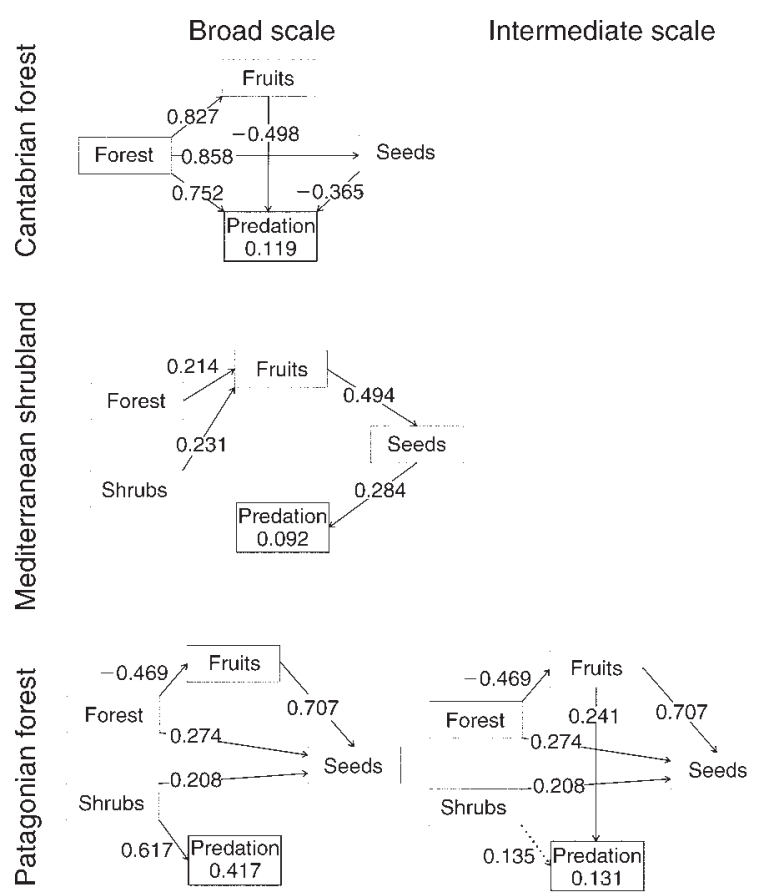

FIG. 7. Structural equation models relating the rate of seed predation (Predation) predicted by the principal coordinates of neighbor matrices (PCNM)-based spatial submodels at broad and intermediate spatial scales to the abundance of fruits (Fruits), the frequency of occurrence of seeds or the abundance of seeds (Seeds), tree canopy cover (Forest), and cover of understory shrubs (Shrubs) in the three study systems. See Fig. 6 for path scheme and significance details. 
Our results for the Patagonian forest suggest a somewhat different scenario for broadscale frugivory, as clumpiness in bird abundance was more sensitive to forest cover than to fruit availability. As has been previously suggested (e.g., Deferrari et al. 2001), birds avoided the more open, low-protective, non-forested habitat patches, gathering in denser forest sectors. There, they searched for fruit-rich patches, even given the fact that understory fruit production was lower in these highly covered sectors than in forest gaps. A lower dietary dependence on fleshy fruits (probably favored by a comparatively larger availability of forest insects during the fruiting season; Amico and Aizen 2005) and a more territorial, sedentary behavior (Tellería and Pérez-Tris 2007) in the dominant bird E. albiceps would also explain the stronger response to habitat features in the Patagonian forest, compared to that of Turdusdominated guilds in the other systems.

The role of environmental correlates on the patchiness of frugivore abundance scaled down to finer spatial scales. In the Cantabrian forest, although diluted, we still found trends of positive responses to fruit availability and forest cover. In contrast, in the Patagonian forest, we found an example of amplification of the patterns of fruit resource tracking when moving down the scale gradient.

\section{Spatial scale and environmental correlates of seed predation}

Seed predation by rodents also showed a multi-scaled and patchy spatial pattern in all study sites. Compared to those of frugivorous birds, the patches of seed predator activity were larger and, except in the case of the Mediterranean shrubland, mostly occurred at a broad scale. Previous works focusing on rodent foraging have found that predictable spatial patterns of seed predation mostly occur at large rather than at fine scales (Bowers and Dooley 1993, Kollmann 2000). This fact seems counterintuitive for animals with relatively small individual home ranges (1000-6000 $\mathrm{m}^{2}$, for $A$. sylvaticus; Wolton and Flowerdew 1985). Thus, the large-scale patterns of predator activity shown here were probably shaped by the spatial response of the whole rodent population (or even metapopulation).

As described in the case of frugivory by birds, the broadscale patterns of seed predation were also partially explained by habitat structure and, to a lesser extent, by the abundance of fruit and seed resources. However, we found no common, across-site factor affecting the spatial patterns of seed predation. In fact, stronger predation occurred in patches of dense forest in the Cantabrian forest but in sectors of dense shrub in the Patagonian forest (see Caccia et al. [2006] for a similar result). The differences in structural complexity between systems, the Cantabrian forest being practically devoid of shrubs but the Patagonian forest having a multi-layer canopy structure, could underpin the relative role of each habitat feature. Regardless of this, and as suggested for other temperate ecosystems (Bowers and Dooley 1993, Hulme and Kollmann 2005), selection by rodents in favor of the most covered, and hence more protective, low-predation-risk habitat sectors could explain the aggregation of seed predation in both these study systems. In the Mediterranean shrubland, habitat features affected the broadscale distribution of seed predation, but these effects were indirect, as high forestand shrub-cover areas favored increased fruit production and, through an increased activity of frugivorous birds, larger availability of seed resources for rodents. These indirect effects agreed with a previous investigation in the same study site that associated large-scale patterns of seed predation to landscape patchiness and shrub cover (Matías et al. 2009).

Our results also indicated some effects of the availability of fruit and seed resources on seed predation at a broad scale, but the sign of these effects differed between systems. The effect of seed availability on seed predation rates must be interpreted cautiously, as some methodological constraints in the estimation of seed abundance in the Cantabrian forest and the Mediterranean shrubland (i.e., some uncontrolled seed loss from open-ground quadrats) may potentially have diluted correlation strength in SEMs from these ecosystems. In any case, we found some trends of seed resource tracking by rodents in the Mediterranean shrubland (see also García et al. 2001). Contrastingly, seed predation was lower in fruit- and seed-rich patches in the Cantabrian forest, even considering that fruit production and seed availability were higher in those high-cover forest sectors that favored seed predators (Fig. 5). Such a negative density-dependent pattern suggests a process of large-scale seed predator satiation (Curran and Webb 2000), probably promoted by the high fruit production and wide occurrence of dispersed seeds during the sampling year (a masting event in Ilex aquifolium; Martínez et al. 2008). Finally, in the Patagonian forest we found multi-scaled determinants of seed predation. Shrub cover was a factor promoting seed predator activity at several scales along the spatial gradients, as both broadscale and intermediate-scale patches of predation matched in space the areas of high shrub cover.

\section{Do resource-habitat balances explain the scale of plant-animal interactions?}

Once we established the links between the spatial structure of frugivory and seed predation and the environmental correlates (resource availability and habitat features) at different spatial scales, we sought to interpret these links within a framework of scaledependent balances (Mayor et al. 2009). This approach states that resource rewards and predation risks are two major limiting factors whose effects on animal spatial distribution may trade off over a gradient of spatial scale (e.g., Mysterud et al. 1999, Dussault et al. 2005, Hebblewhite and Merrill 2009, Mayor et al. 2009). 
Thus, the expression of trade-offs would correspond to the amplification of resource tracking at the expense of a dilution of predation risk, or vice versa, when scaling up or down (Mayor et al. 2009).

Assuming that habitat structures represent the degree of protection for frugivores and granivores against their own predators (Sapir et al. 2004, Fedriani and Manzaneda 2005), our results suggest that the spatial scale of plant-animal interactions may be ultimately explained in terms of the balance between resource acquisition and predator avoidance. This is in fact suggested by patterns found in the Patagonian forest, where the amplification of fruit resource tracking by birds was simultaneous to the loss of forest cover effects when scaling down. In other words, the selection for highly covered patches at the large scale freed frugivorous birds from the need to make resource-protection trade-offs at a finer scale, rendering their activity independent of habitat features. Similar trade-off trends emerged for seed predation, as the strength of shrub cover effects decreased and the positive effects of resource availability (fruits) increased when scaling down. In sum, we would argue for a comprehensive viewpoint to explain the spatial scale of plant-animal interactions (Fig. 1), which considers, firstly, the spatial match between plant resources and animal activity, as a function of the degree of resource spatial heterogeneity and animal perceptive scale, and, secondly, the constraining effects of habitat structure, as a trading-off mechanism able to dilute scale-dependent resource tracking.

\section{Constraints on predictive resource-habitat models}

On the whole, we found a generalized moderate-tolow predictability in SEMs applied to our data (Figs. 6 and 7). This fact suggests that much of the patchiness in both frugivory and seed predation remained unexplained by the combined effects of resource availability and habitat features. Two reasons may explain these constraints. First, other mechanisms may actually be contributing to the generation of clumpiness in both frugivory and seed predation. Among these mechanisms, intrinsic population processes, such as dispersal limitation in the case of predatory rodents (Wolton and Flowerdew 1985) or wintering aggregative behavior in the case of frugivorous birds (Sridhar et al. 2009), may account for aggregation at finer scales. Similarly, other habitat features, to which our transect-based sampling was blind, might be causing the multi-scaled patchiness in frugivore abundance and seed predation. For example, small-scale patchiness may depend on soil suitability for burrowing (in the case of granivory; e.g., Wolton and Flowerdew 1985), whereas large-scale patchiness may depend on forest fragment size, the degree of forest isolation, or the quantity of forest edge (Santos and Tellería 1994, Tewksbury et al. 2002).

Second, the predictive power of SEMs may be constrained by the prior use of PCNM methodology (Borcard et al. 2004). In this sense, the use of values predicted by spatial submodels (i.e., resulting from linear models relating raw frugivory and seed predation values to PCNM spatial templates) could represent, in some way, the introduction of spatial variability in the response variables, which may dilute the actual correlations between these biological responses and the environmental variables. Thus, further development of techniques of spatially explicit analysis are needed in order to retain the advantages of PCNM as presented here (i.e., the accurate dissection of the spatial structure of ecological data along continuous spatial extents) while, at the same time, provide precise measures of scale-dependent biological responses to be linked to environmental factors.

\section{Consequences of the scale of plant-animal interactions: balance between interactions}

We studied two plant-animal interactions of opposite sign (that of mutualistic frugivory and concomitant seed dispersal vs. that of antagonistic post-dispersal seed predation) subsequently linked through the regeneration cycle of woody plants. We therefore aimed to interpret our results in terms of the demographic outcome of the scale-dependent balance between these two interactions. In this sense, it is known that seed predators may screenoff the spatial patterns of recruitment initially imposed by seed disperses (i.e., the seed rain template), but these disrupting effects depend largely on the spatial scale of seed predation (García et al. 2005b). Namely, seed predation may disrupt the spatial patterns of recruitment when operating at the same, or finer, scale than seed dispersal.

In our case, we make the assumption that the spatial match between the abundances of fruits and frugivores is indicative of stronger frugivore activity in fruit-rich landscape sectors and, hence, of disproportionate seed deposition within the spatial extent occupied by fruiting plants. This is supported by previous works in the same systems, explicitly linking frugivore abundance to seed dispersal magnitude across the landscape (Amico and Aizen 2005, García et al. 2010, Zamora et al. 2010) and showing disproportionate dispersal under fruiting plants (García et al. 2001, 2005b). We also assume that our manipulative measures of seed predation were accurate estimates of seed survival in the field. We may, then, interpret the potential spatial effect of seed predation on recruitment by comparing the spatial structure of frugivore abundance and seed predation. As depicted by the dissection of spatial structure after applying PCNM (Figs. 3 and 4) and compared to frugivore abundance, most heterogeneity in seed predation emerged at a larger scale, and, even within each spatial scale, patches of seed predation were larger than those of frugivory. As a consequence of these differences, seed predation should act as a spatially homogeneous demographic filter (at least at the scales studied here) with regard to seed rain, with a net effect of reducing the number of seedlings entering plant populations, but with 
weak effects in recruitment spatial distribution (García et al. 2005b). Therefore, we surmise the existence of large-scale spatial feedback systems in the plant-animal systems studied, given that the spatial structure of plant populations may condition that of frugivores and, conversely, the spatial patterns of plant recruitment may mirror those of frugivore activity. We would further argue that this positive, large-scale spatial feedback between fleshy-fruited plants and frugivorous animals is a generalized form of biological organization in many temperate and tropical systems (García et al. 2009, Wiegand et al. 2009, Fedriani et al. 2010).

\section{Consequences of the scale of plant-animal interactions: redundancy within and across scales}

Plant-animal interactions are crucial nodes in the structure of ecological communities as well as important drivers of ecosystem functioning (Bascompte and Jordano 2007, Schmitz 2008). These structural and functional roles may strongly depend on the degree of redundancy in the spatial performance of interactions. In this sense, redundancy has been defined as an overlap in ecological functions (e.g., seed dispersal) driven by different animals interacting with plants in the same spatiotemporal context (Zamora 2000). Moreover, the replication of a given interaction-driven ecological function across a gradient of spatial scales has also been pinpointed as a form of redundancy (Peterson et al. 1998).

Our results on the spatial structure of frugivore abundance and on the match between fruits and frugivores suggest the existence of both within- and across-scale redundancy in the role of frugivores in temperate systems. In fact, in the Mediterranean shrubland, both the large-bodied Turdus sp. and the smallbodied E. rubecula showed similar patterns of patchiness. Despite the limited power of models predicting frugivore patchiness as a function of fruit availability and habitat features in this system, the single fact that both frugivore types showed a similar trend of response was indicative of functional redundancy. In addition, fruit resource tracking happened at different scales in both the Cantabrian forest and the Patagonian forest. Thus, we assume that redundancy in frugivory will lead to within- and across-scale similarities in the demographic outcomes of seed dispersal service. Within-scale redundancy between frugivore types would mean that the spatial patterns of seed dispersal would be maintained even with a strong decline in, or even the extinction of, some frugivore species. This is a realistic scenario, bearing in mind that the wintering populations of many Turdus species are decreasing in southern Europe due to northward retraction of the wintering areas or population decline in breeding areas (Rivalan et al. 2007). Across-scale redundancy would involve that the seed dispersal service, affected by the match between fruits and birds, would respond in similar terms to disturbance at different spatial scales, both over landscape extents and within patches in a given landscape. This is a crucial aspect in terms of forest recovery in the degraded landscapes of the systems studied, as tree recruitment is largely controlled by seed dispersal (García et al. 2005b, Zamora et al. 2010). In sum, both within- and across-scale redundancy in frugivory patterns may ultimately contribute to resilience (Peterson et al. 1998, Elmqvist et al. 2003) in the temperate ecosystems studied herein.

\section{Conclusions}

We studied two different plant-animal interactions, frugivory by birds and seed predation by rodents, acting sequentially through the regeneration cycle of fleshyfruited trees and shrubs from three temperate systems. We evidenced that these plant-animal interactions operated at different spatial scales in comparable environmental settings, but that the same guild of interacting animals may have rather similar spatial responses across different systems. The dimensions of spatial aggregates in the abundance of frugivorous birds and the rate of seed predation, along with the allocation of their spatial variability along a gradient of scale, suggests that seed predation shows a larger operational scale than frugivory by birds. This interpretation seems counterintuitive, bearing in mind the differences between animal types in their perceptive scales, supposedly determined by body size and vagility (larger in birds than in rodents).

Nevertheless, the spatial distributions of frugivory and seed predation may be ultimately explained in terms of a scale-dependent response of animals to plant resource availability and habitat structure. Frugivorous birds tracked the abundance of fruits at large spatial scales in each system studied, and, within some systems, even across consecutive spatial scales. In those systems with a more complex habitat structure, habitat features had a stronger effect than fruit availability on the largescale patterns of bird abundance. In comparison to frugivory, the large-scale determinants of seed predation were more idiosyncratic for each study system. Seed predation distribution was scarcely affected by plant resource availability, but was more responsive to habitat features that represented protection against predation. A reward-risk trade-off could finally explain the scaledependent effect of resource availability and habitat features in plant-animal interactions. We encourage the consideration of the spatial scale as a key issue in understanding plant-animal interaction systems, due to its consequences on the development of community sorting forces, such as demographic positive feedbacks, and its effects on ecosystem resilience, mediated by redundancy in vegetation regeneration processes.

\section{ACKNOWLEDGMENTS}

We thank M. Rodríguez-Cabal, S. García, D. Martínez, A. Valdés, L. Matías, A. Herrero, J. A. Hódar, and J. M. Herrera for help with field work. We also thank the Parque Nacional de Sierra Nevada and the Parque Municipal Llao-Llao for 
permission to carry out work in the parks and M. Aizen for logistical support. Elizabeth Borer, Johannes Kollmann, and one anonymous referee provided helpful suggestions on a previous version of the manuscript. Ronnie Lendrum corrected the English style of the text. This research was funded by the projects BIOCON03-162 (BBVA Foundation) and CGL200801275 (MICINN) to D. García and CGL2008-04794 (MICINN) and RNM 1890 (Junta de Andalucía) to R. Zamora.

\section{Literature Cited}

Aizen, M. A., D. P. Vázquez, and C. Smith-Ramirez. 2002. Historia natural y conservación de los mutualismos plantaanimal del bosque templado de Sudamérica austral. Revista Chilena de Historia Natural 75:79-97.

Amico, G. C., and M. A. Aizen. 2005. Dispersión de semillas por aves en un bosque templado de Sudamérica austral: ¿quién dispersa a quién? Ecología Austral 15:89-100.

Amico, G. C., M. A. Rodríguez-Cabal, and M. A. Aizen. 2009. The potential key seed-dispersing role of the arboreal marsupial Dromiciops gliroides. Acta Oecologica 35:8-13.

Arbuckle, J. L. 2007. Amos 16.0: user's guide. SPSS, Chicago, Illinois, USA.

Bascompte, J., and P. Jordano. 2007. Plant-animal mutualistic networks: the architecture of biodiversity. Annual Review of Ecology, Evolution and Systematics 38:568-593.

Borcard, D., and P. Legendre. 2002. All-scale spatial analysis of ecological data by means of principal coordinates of neighbour matrices. Ecological Modelling 153:51-68.

Borcard, D., and P. Legendre. 2004. SpaceMaker2: user's guide. Département de Sciences Biologiques, Université de Montréal, Montréal, Quebec, Canada.

Borcard, D., P. Legendre, C. Avois-Jacquet, and H. Tuomisto. 2004. Dissecting the spatial structure of ecological data at multiple scales. Ecology 85:1826-1832.

Bowers, M. A., and J. L. Dooley. 1993. Predation hazard and seed removal by small mammals: microhabitat versus patch scale effects. Oecologia 94:247-254.

Bowyer, R. T., and G. K. Kie. 2006. Effects of scale on interpreting life-history characteristics of ungulates and carnivores. Diversity and Distributions 12:244-257.

Burns, K. C. 2004. Scale and macroecological patterns in seed dispersal mutualism. Global Ecology and Biogeography 13: 289-293.

Caccia, F. D., E. J. Chaneton, and T. Kitzberger. 2006. Trophic and non-trophic pathways mediate apparent competition through post-dispersal seed predation in a Patagonian mixed forest. Oikos 113:469-480.

Curran, L. M., and C. O. Webb. 2000. Experimental tests of the spatiotemporal scale of seed predation in mast-fruiting Dipterocarpaceae. Ecological Monographs 70:129-148.

Deferrari, G., C. Camilión, G. Martínez, and P. L. Peri. 2001. Changes in Nothofagus pumilio forest biodiversity during the forest management cycle. 2. Birds. Biodiversity and Conservation 10:2093-2108.

Díaz, I., C. Papic, and J. J. Armesto. 1999. An assessment of post-dispersal seed predation in temperate rain forest fragments in Chiloé Island, Chile. Oikos 87:228-238.

Dussault, C., J.-P. Ouellet, R. Courtois, J. Huot, L. Breton, and H. Jolicoeur. 2005. Linking moose habitat selection to limiting factors. Ecography 28:619-628.

Elmqvist, T., C. Folke, M. Nyström, G. Peterson, J. Bengtsson, B. Walker, and J. Norberg. 2003. Response diversity, ecosystem change, and resilience. Frontiers in Ecology and Environment 1:488-494.

Fauchald, P., K. E. Erikstad, and H. Skarsfjord. 2000. Scale dependent predator-prey interactions: the hierarchical spatial distribution of seabirds and prey. Ecology 81:773-783.

Fedriani, M. J., and A. J. Manzaneda. 2005. Pre- and postdispersal seed predation by rodents: balance of food and safety. Behavioural Ecology 16:1018-1024.
Fedriani, M. J., T. Wiegand, and M. Delibes. 2010. Spatial pattern of adult trees and the mammal-generated seed rain in the Iberian pear. Ecography. [doi: 10.1111/j.16000587.2009.06052.x]

García, D., and N. P. Chacoff. 2007. Scale-dependent effects of habitat fragmentation on hawthorn pollination, frugivory and seed predation. Conservation Biology 21:400-411.

García, D., J. R. Obeso, and I. Martínez. 2005a. Rodent seed predation promotes differential recruitment among birddispersed trees in temperate secondary forests. Oecologia 144:435-446.

García, D., J. R. Obeso, and I. Martínez. 2005b. Spatial concordance between seed rain and seedling establishment in bird-dispersed trees: Does scale matter? Journal of Ecology 93:693-704.

García, D., and R. Ortiz-Pulido. 2004. Patterns of resource tracking by avian frugivores at multiple spatial scales: two case studies on discordance among scales. Ecography 27:187196.

García, D., M. A. Rodríguez-Cabal, and G. C. Amico. 2009. Seed dispersal by a frugivorous marsupial shapes the spatial scale of a mistletoe population. Journal of Ecology 97:217229.

García, D., R. Zamora, and G. C. Amico. 2010. Birds as suppliers of seed dispersal in temperate ecosystems: conservation guidelines from real-world landscapes. Conservation Biology. [doi: 10.1111/j.1523-1739.2009.01440.x]

García, D., R. Zamora, J. M. Gómez, and J. A. Hódar. 2001. Frugivory at Juniperus communis depends more on population characteristics than on individual attributes. Journal of Ecology 89:639-647.

García-Castaño, J. L., J. Kollmann, and P. Jordano. 2006. Spatial variation of post-dispersal seed removal by rodents in highland microhabitats of Spain and Switzerland. Seed Science Research 16:213-222.

Grace, J. B. 2006. Structural equation modeling and natural systems. Cambridge University Press, Cambridge, UK.

Guitián, J., and T. Bermejo. 2006. Dynamics of plant-frugivore interactions: a long-term perspective on holly-redwing relationships in northern Spain. Acta Oecologica 30:151-160.

Guitián, J., and I. Munilla. 2008. Resource tracking by avian frugivores in mountain habitats of northern Spain. Oikos 117:265-272.

Hebblewhite, M., and E. Merrill. 2009. Trade-offs between predation risk and forage differ between migrant strategies in a migratory ungulate. Ecology 90:3445-3454.

Herrera, J. M., and D. García. 2009. The role of remnant trees on seed dispersal through the matrix: being alone is not always so sad. Biological Conservation 142:149-158.

Holt, R. D. 2002. Food webs in space: on the interplay of dynamic instability and spatial processes. Ecological Research 17:261-273.

Hulme, P. E., and J. Kollmann. 2005. Seed predators guilds, spatial variation in post-dispersal seed predation and potential effects on plant demography: a temperate perspective. Pages 9-30 in P. M. Forget, J. E. Lambert, P. E. Hulme, and S. B. Vander Wall, editors. Seed fate: predation, dispersal and seedling establishment. CABI, Wallingford, UK.

Inouye, B. D. 1999. Integrating nested spatial scales: implications for the coexistence of competitors on a patchy resource. Journal of Animal Ecology 68:150-162.

Kitzberger, T., E. J. Chaneton, and F. D. Caccia. 2007. Indirect effects of prey swamping: differential seed predation during a bamboo masting event. Ecology 88:2541-2554.

Kneitel, J. M., and J. M. Chase. 2004. Trade-offs in community ecology: linking spatial scales and species coexistence. Ecology Letters 7:69-80.

Kollmann, J. 2000. Dispersal of fleshy-fruited species: A matter of spatial scale? Perspectives in Plant Ecology, Evolution and Systematics 3:29-51. 
Kotliar, N. B., and J. A. Wiens. 1990. Multiple scales of patchiness and patch structure: a hierarchical framework for the study of heterogeneity. Oikos 59:253-260.

Leiss, K. A., and P. G. L. Klinkhamer. 2005. Spatial distribution of nectar production in a natural Echium vulgare population: implications for pollination behaviour. Basic and Applied Ecology 6:317-324.

Levin, S. A. 1992. The problem of pattern and scale in ecology. Ecology 73:1943-1976.

Levin, S. A. 2000. Multiple scales and the maintenance of biodiversity. Ecosystems 3:498-506.

Martínez, I., D. García, and J. R. Obeso. 2008. Differential seed dispersal patterns generated by a common assemblage of vertebrate frugivores in three fleshy-fruited trees. Écoscience 15:189-199.

Matías, L., I. Mendoza, and R. Zamora. 2008. Seed dispersal patterns by large frugivorous mammals in a degraded mosaic landscape. Restoration Ecology. [doi: 10.1111/j.1526100X.2008.00475.x]

Matías, L., I. Mendoza, and R. Zamora. 2009. Consistent pattern of habitat and species selection by post-dispersal seed predators in a Mediterranean mosaic landscape. Plant Ecology 203:137-147.

Mayor, S. J., J. A. Schaefer, and S. P. Mahoney. 2009. Habitat selection at multiple scales. Écoscience 16:238-247.

Mayor, S. J., J. A. Schaefer, D. C. Schneider, and S. P. Mahoney. 2007. Spectrum of selection: new approaches to detect scale-dependent response to habitat. Ecology 88:16341640 .

McCann, K. S., J. B. Rasmussen, and J. Umbanhowar. 2005. The dynamics of spatially coupled food webs. Ecology Letters 8:513-523.

Mysterud, A., L. B. Lian, and D. O. Hjermann. 1999. Scaledependent trade-offs in foraging by European roe deer (Capreolus capreolus) during winter. Canadian Journal of Zoology 77:1486-1493.

Peters, D. P. C., B. T. Bestelmeyer, and M. C. Turner. 2007. Cross-scale interactions and changing pattern-process relationships: consequences for system dynamics. Ecosystems 10: 790-796.

Peterson, D. L., and V. T. Parker. 1998. Dimensions of scale in ecology, resource management, and society. Pages 499-522 in D. L. Peterson and V. T. Parker, editors. Ecological scale: theory and applications. Columbia University Press, New York, New York, USA.

Peterson, G. D. 2000. Scaling ecological dynamics: selforganization, hierarchical structure, and ecological resilience. Climatic Change 44:291-309.

Peterson, G., C. R. Allen, and C. S. Holling. 1998. Ecological resilience, biodiversity, and scale. Ecosystems 1:6-18.

Rey, P. J. 1995. Spatio-temporal variation in fruit and frugivorous bird abundance in olive orchards. Ecology 76: $1625-1635$.

Rivalan, P., M. Frederiksen, G. Loïs, and R. Julliard. 2007. Contrasting responses of migration strategies in two European thrushes to climate change. Global Change Biology 13: 275-287.

Santos, T., and J. L. Tellería. 1994. Influence of forest fragmentation on seed consumption and dispersal of Spanish juniper Juniperus thurifera. Biological Conservation 70:129134.

Sapir, N., A. Abramsky, E. Shochat, and I. Izhaki. 2004. Scaledependent habitat selection in migratory frugivorous passerines. Naturwissenschaften 91:544-547.

Saracco, J. F., J. A. Collazo, and M. J. Groom. 2004. How do frugivores track resources? Insights from spatial analyses of bird foraging in a tropical forest. Oecologia 139:235-245.

Schaefer, J. A., and F. Messier. 1995. Habitat selection as a hierarchy: the spatial scales of winter foraging by musk oxen. Ecography 18:333-344.
Schmitz, O. J. 2008. Herbivory: from individuals to ecosystems. Annual Review of Ecology, Evolution and Systematics 39: $133-152$.

Snyder, R. E., and P. Chesson. 2004. How the spatial scales of dispersal, competition, and environmental heterogeneity interact to affect coexistence. American Naturalist 164:633650.

Spiegel, O., and R. Nathan. 2007. Incorporating dispersal distance into the disperser effectiveness framework: frugivorous birds provide complementary dispersal to plants in a patchy environment. Ecology Letters 10:718-728.

Sridhar, H., G. Beauchamp, and K. Shanker. 2009. Why do birds participate in mixed-species foraging flocks? A largescale synthesis. Animal Behaviour 78:337-347.

Szabó, P., and G. Meszéna. 2006. Spatial ecological hierarchies: coexistence on heterogeneous landscapes via scale niche diversification. Ecosystems 9:1009-1016.

Tellería, J. L., and J. Pérez-Tris. 2003. Seasonal distribution of a migratory bird: effects of local and regional resource tracking. Journal of Biogeography 30:1583-1591.

Tellería, J. L., and J. Pérez-Tris. 2007. Habitat effects on resource tracking ability: Do wintering Blackcaps Sylvia atricapilla track fruit availability? Ibis 149:18-25.

Tellería, J. L., A. Ramírez, and J. Pérez-Tris. 2005. Conservation of seed-dispersing migrant birds in Mediterranean habitats: shedding light on patterns to preserve processes. Biological Conservation 124:493-502.

Tellería, J. L., A. Ramírez, and J. Pérez-Tris. 2008. Fruit tracking between sites and years by birds in Mediterranean wintering grounds. Ecography 31:381-388.

Tewksbury, J. J., D. J. Levey, N. M. Haddad, S. Sargent, J. L. Orrock, A. Weldon, B. J. Danielson, J. Brinkerhoff, E. Damschen, and P. Townsend. 2002. Corridors affect plants, animals, and their interactions in fragmented landscapes. Proceedings of the National Academy of Sciences USA 99: 12923-12926.

Thompson, J. N. 2002. Plant-animal interactions: future directions. Pages 236-247 in C. M. Herrera and O. Pellmyr, editors. Plant-animal interactions: an evolutionary approach. Blackwell Science, Oxford, UK.

Turner, M. G., R. H. Gardner, and R. V. O’Neill. 2001. Landscape ecology in theory and practice: pattern and process. Springer-Verlag, New York, New York, USA.

Van Koppel, J., A. Bardgett, R. J. Bengtsson, C. RodriguezBarrueco, M. Rietkerk, M. Wassen, and V. Wolters. 2005. The effects of spatial scale on trophic interactions. Ecosystems 8:801-807.

WallisDeVries, M. F., E. A. Laca, and M. W. Demment. 1999. The importance of scale of patchiness for selectivity in grazing herbivores. Oecologia 121:355-363.

Wehnke, E. V., X. L. Medellín, and E. Ezcurra. 2009. Patterns of frugivory, seed dispersal and predation of blue fan palms (Brahea armata) in oases of northern Baja California. Journal of Arid Environments 73:773-783.

Westphal, C., I. Steffan-Dewenter, and T. Tscharntke. 2006. Bumblebees experience landscapes at different spatial scales: possible implications for coexistence. Oecologia 149:289-300.

Whitney, K. D., and T. B. Smith. 1998. Habitat use and resource tracking by African Ceratogymna hornbills: implications for seed dispersal and forest conservation. Animal Conservation 1:107-117.

Wiegand, T., I. Martínez, and A. Huth. 2009. Recruitment in tropical tree species: revealing complex spatial patterns. American Naturalist 174:E106-E140.

Wiens, J. A. 1989. Spatial scaling in ecology. Functional Ecology 3:385-397.

Wolton, R. J., and J. R. Flowerdew. 1985. Spatial distribution and movements of wood mice, yellow-necked mice, and bank voles. Symposia of the Zoological Society of London 55:249 275 
Zamora, R. 2000. Functional equivalence in plant-animal interactions: ecological and evolutionary consequences. Oikos 88:442-447.
Zamora, R., J. A. Hódar, L. Matías, and I. Mendoza. 2010. Positive adjacency effects mediated by seed disperser birds in pine plantations. Ecological Applications 20:1053-1060.

\section{APPENDIX A}

Geographical locations of the study sites (Ecological Archives XX-XXX-XXXX).

\section{APPENDIX B}

Summary of the steps to develop the principal coordinates of neighbor matrices (PCNM) analysis in the studied framework (Ecological Archives XX-XXX-XXXX). 